Gerión. Revista de Historia Antigua

ISSN: 0213-0181

https://dx.doi.org/10.5209/geri.74789

\title{
Aqua mater: a vueltas con el teónimo Betatun ${ }^{1}$
}

\author{
Antonio Carlos Ledo Caballero ${ }^{2}$
}

Recibido: 18 de diciembre de 2019 / Aceptado: 31 de octubre de 2020

Resumen. La aparición en el entorno del santuario tardoibérico de Las Atalayuelas (Fuerte del Rey - Torredelcampo, Jaén) de una inscripción en la que se documenta el teónimo ibérico Betatun abre nuevas perspectivas en el estudio de la religión ibérica. Con el presente artículo intentamos demostrar que en el nombre de la divinidad está implícito un elemento común que lo relacionaría con una serie de topónimos e hidrónimos, tanto antiguos como modernos, y que no es otro que el agua.

Palabras clave: dioses ibéricos; santuarios ibéricos; sincretismos; toponimia; hidronimia.

\section{[en] Aqua Mater: On the Meaning of the Theonym Betatun}

Abstract. The finding of an inscription containing the Iberian theonym Betatun in the surrounding area of the Late Iberian sanctuary in Las Atalayuelas site (Fuerte del Rey - Torredelcampo, Jaén) opens up new perspectives for the study of Iberian religion. In this paper we try to demonstrate that in the name of the divinity is implicit a common element that would relate it to several toponyms and hydronyms, both ancient and modern, and this is water.

Key words: Iberian Gods; Iberian Shrines; Syncretisms; Toponymy; Hydronymy.

Sumario: 1. Introducción. 2. El santuario tardoibérico de Las Atalayuelas (Fuerte del Rey Torredelcampo, Jaén). 3. Betatun, teónimo ibérico. 4. "Una fecundidad sincrética". 5. Agua y culto. 6. La cercana y acuática Deva. 7. Conclusión. 8. Referencias bibliográficas.

Cómo citar: Ledo Caballero, A. C. (2021): Aqua mater. A vueltas con el teónimo Betatun, en Gerión $39 / 1,221-245$.

\footnotetext{
1 Vaya por delante mi agradecimiento a mi compañero y amigo Xaverio Ballester, sin cuya inestimable ayuda estas páginas jamás hubieran visto la luz.

2 Universitat de València.

E-mail: Antonio.Ledo@uv.es

ORCID: 0000-0003-3123-526X
} 
Porque no constituye la toponimia en sí un mero saber de tipo lingüístico, como se cree. Es un saber que está en relación, en conexión, con la historia del hombre y con el mundo circundante, con el mundo que le rodea, y, por tanto, al referirlo a una pura situación lingüística de un momento dado podría desenfocar la realidad. ${ }^{3}$

\section{Introducción}

En un estudio aparecido en 1909, Schuchardt consideraba que la palabra vasca ibai ("río"), procedente de un supuesto *ibait, estaba presente en tres nombres geográficos mencionados en las fuentes escritas, concretamente Baetis, Baetulo y Baeterrae, nombres cuyos significados se explicaban, respectivamente, como "río", "ciudad del río" y "lugar del río". ${ }^{4}$ Recogiendo la idea del lingüista alemán, en un trabajo publicado con ocasión del merecido homenaje al profesor Montenegro Duque hace ya más de veinte años, planteamos que los nombres antiguos referidos podían compartir raíz con una serie de topónimos actuales vinculados a lugares en los que resulta evidente la presencia abundante del agua. ${ }^{5} \mathrm{~A}$ los ejemplos aducidos entonces podemos añadir ahora otros casos, como aquellos en los que vuelve a manifestarse la relación con el líquido elemento de la forma Beteta, nombre del manantial más importante del murciano término de Mazarrón según Madoz,así como de un barranco que discurre entre los términos de Albuñol (Granada) y Adra (Almería). ${ }^{6}$ Por último, cabría considerar también, con las debidas cautelas, la interesante serie de hidrónimos vascos que contienen el segmento beta. ${ }^{7}$

Caro Baroja 1986, 122.

4 Schuchardt 1909, 465-466. Véase también Álvarez 1951; Faria 2008, 66; Silgo 2013, 73-78. Para Untermann (2018, en adelante MLH VI), las formas Baeturia, Baetulo, *Baedro/Baebro y Betterri comparten raíz con Baetis ( $M L H$ VI, 239-245, 270-271), hidrónimo este último que considera un apelativo derivado de la voz ibérica baites, la cual “es könnte 'Fluss' oder 'fliessen' bedeutet haben” (MLH VI, 241). Contra Villar (2001, 263-264), que explicaba a partir de una filiación indoeuropea los topónimos Baetis y Baetulo, incluyéndolos en una serie (bai) atestiguada desde el sur peninsular hasta los Pirineos, así como por regiones de la Europa occidental y báltica.

$5 \quad$ Ledo 1999.

6 Véase también Guillén 2014, 77. La forma Beteta se repite como hidrónimo o topónimo en más de diez ocasiones por diversas áreas del oriente peninsular. En un estudio por publicar intentamos demostrar que en la mayoría de estos casos puede verificarse su relación con el agua.

7 Hemos utilizado el Nomenclátor Geográfico de la CAV, aplicación digital editada por el Departamento de Cultura y Lingüística del Gobierno Vasco y disponible en http://www.euskadi.eus/app/nomenclator-geografico-cae/bet/ oficial/consultanomenclator/top-Bet/codcon-2/oficial-s). En la lista aparecen formas como Jubeta (Gordexola, Vizcaya), Ibeta (Aramaio, Álava); Arbetako (Elduaín, Guipúzcoa), Sarobetako (Albiztur, Guipúzcoa), Kobetako (Arrankudiaba, Vizcaya) y Salibeta (Errezil, Guipúzcoa); pero destacaríamos por su significado Iturrabeta, nombre de un manantial de Salvatierra (Álava) y ejemplo de tautotoponimia con los dos componentes pertenecientes a la misma lengua, o a diversos estadios de la misma. El fenómeno es detectable también en otros hidrónimos peninsulares, tanto en los elocuentes Fuente de la Hontana (Castillo de Locubín, Jaén) o Fuente de la Hontanilla (Sepúlveda, Segovia), como en los más opacos, como Fuente Juntoria (La Vecilla, León) o Fuente de la Juan Fría, 


\section{El santuario tardoibérico de Las Atalayuelas (Fuerte del Rey-Torredelcampo, Jaén)}

El motivo de recordar aquel trabajo tiene que ver con un importante hallazgo llevado a cabo en el lugar arqueológico de Las Atalayuelas, situado a caballo entre los términos jienenses de Fuerte del Rey y Torredelcampo. El yacimiento es conocido desde $1920,{ }^{8}$ pero hay que esperar hasta 1987 para que tenga lugar la primera actuación arqueológica bajo la dirección de Castro López. ${ }^{9}$ En 2002 se perpetra un importante expolio que impulsa a las autoridades andaluzas a realizar una intervención de urgencia centrada en la ladera sur del llamado Cerro de las Norias, unas de las unidades topográficas que conforman el yacimiento. ${ }^{10}$ Se identificó así un santuario, activo entre el siglo II a.C. y mediados del siglo I d.C., adosado a los restos de lo que había sido un oppidum surgido en el Ibérico Antiguo. ${ }^{11}$ Sobre parte de la superficie que ocupaba el asentamiento indígena aparecerá una ciudad romana, abandonada finalmente en el siglo II d.C. ${ }^{12}$ Los aproximadamente $60 \mathrm{~m}$ que separaban el santuario de una de las puertas de la ciudad autorizan a definirlo como suburbano (mejor tal vez que "periurbano") en tanto que ubicado en el exterior del recinto amurallado pero dentro del radio urbano de control efectivo y simbólico. ${ }^{13} \mathrm{La}$ excavación documentó un heterogéneo conjunto votivo compuesto por abundantes restos cerámicos, elementos de adorno, placas decorativas, monedas, armas y exvotos. Entre estos últimos destacan dos raros ejemplares elaborados en hierro que representan a un hombre y una mujer con evidente resaltado de sus órganos sexuales, especialmente en el caso de la figura femenina, todo lo cual parece conectar con ritos propiciatorios de fecundidad y/o fertilidad, ${ }^{14}$ un aspecto interesante para el objetivo de estas líneas, como tendremos ocasión de comprobar.

\section{Betatun, teónimo ibérico}

Pero no son estas cuestiones las que nos han llevado a la elaboración del presente trabajo, sino un pequeño cipo (entre 9 y $12 \mathrm{~cm}$ de alto por 10 de ancho) de caliza blanca aparecido a raíz del expolio señalado. La pieza, que se ha puesto en relación con el santuario tardoibérico que acabamos de mencionar, ${ }^{15}$ presenta el siguiente epígrafe:

repetido, entre otros, en el municipio conquense de Masegosa, en el abulense de Cebreros (Nieto 2000, 398-399) y similar al asturiano Juente Juantirnia (Ballester 2013, 196).

Cazabán 1920; Molinos et alii 2005, 628.

Castro et alii 1990 .

Molinos et alii 2005, 628; Rueda et alii 2015, 424.

Molinos - Rueda 2011, 222; Rueda et alii 2015, 424.

Ruiz et alii 2005, 79.

Quesada - Rueda 2017, 38-39.

4 Estos exvotos han sido interpretados como "reminiscencia de un rito de tradición, revivido en un contexto fechado en el siglo I a. C.” (Grau - Rueda 2014, 116; vid. también Ruiz et alii 2005, 84-85; Rueda et alii 2015, 303).

15 Corzo et alii 2007, 251-253; Rueda et alii 2015, 423, fig. 1; Morena 2017, 97-98. 


\section{Betatun \\ Aelia $\cdot$ Belesiar \\ sorte $\cdot \operatorname{ius}(s) u$ \\ $v($ otum $) \cdot s($ olvit $) \cdot l($ ibens $) \cdot m(\text { erito })^{16}$}

La inscripción posee un valor extraordinario por diversos motivos. La fórmula sorte iusu, ${ }^{17}$ que hace referencia al método de comunicación con la divinidad mediante el lanzamiento o extracción de elementos como guijarros, tablillas, discos, etc., la convierten en el primer testimonio de cleromancia en la Península Ibérica. ${ }^{18}$ Pero lo que confiere a esta inscripción un carácter único es la aparición del nombre de la entidad divina a la que va dirigida la ofrenda, Betatun, ${ }^{19}$ considerado casi unánimemente como el primer teónimo ibérico inequívoco ${ }^{20}$ conservado en "grado cero", esto es, no sometido al habitual proceso de interpretatio causante de que el nombre de varias divinidades ibéricas, documentadas epigráfica o literariamente, nos haya llegado con la forma asimilada a la de los dioses del panteón greco-romano. ${ }^{21}$

No se puede afirmar con seguridad el género de la divinidad que hay detrás del nombre Betatun, ${ }^{22}$ aunque ciertos elementos autorizan a conjeturar en este sentido. Se ha tenido en cuenta, además de que fuera una mujer la dedicante de la inscripción, el predominio de las diosas en el panorama religioso del valle alto del Guadalquivir en época ibérica, diosas que si bien adoptan fórmulas iconográficas distintas, como la Hathor de Cástulo, la Dama de Galera o la figura de las arracadas de Santiago de la Espada entre otras, comparten el rasgo común de simbolizar el poder fecundo de la naturaleza. ${ }^{23}$ Estas mismas diosas aparecen bien arraigadas desde época

16 HEp 16, 2007, 446. La lectura presentada es la que hiciera Orduña (2009), que rechazó la propuesta para la segunda línea de Corzo et alii $(2007,253)$ en la que se quería ver la referencia a la colocación de un altar: Aelia - Belesi (scil. filia?) · ar(am scil. posuit); la lectura de Orduña es refrendada, entre otros, por de Hoz 2015, 406; Velaza 2015, 291; Marco 2018, 305.

17 La forma iusu (por iussu, equivalente aquí a [sorte] iussa) ha sido considerada como una grafía arcaica que acabó desapareciendo a lo largo del siglo I a.C. Esta peculiaridad, algunos indicios paleográficos y el nombre de la dedicante permiten datar la inscripción con bastante probabilidad en la segunda mitad del siglo I a.C. (Corzo et alii 2007, 258-259).

18 Corzo et alii $2007,259$.

19 A pesar de la esperable desinencia de dativo, la forma no presenta marca de caso alguna, ni latina ni ibérica, situación idéntica a la de los nombres de los soldados (y los de sus padres) que aparecen en el conocido Bronce de Ascoli (Corzo et alii 2007, 255 y n. 11).

20 Corzo et alii 2007. La misma opinión en de Hoz 2015, 406; Marco 2018, 305; dudas expresadas por Velaza 2015, 291, n. 16; Rodríguez Ramos 2019, 263. Por su parte, Orduña $(2009,359)$ reconocía que "esta es la primera ocasión en que el contexto no ofrece duda, ni parecen plantearse en principio dudas sobre el carácter ibérico del nombre", si bien recordaba otras propuestas de identificación como Neitin; sobre este último, Almagro Gorbea 2002; Corzo et alii 2007, 256; Rodríguez Ramos 2019, 265-269. Otras propuestas de teónimos ibéricos han sido las de Bokon (Silgo 1988, 70-71, y 1994, 88), considerado en su día como "el único nombre de divinidad ibérica conocida" (Moneo 2003, 202), iumstiŕ, documentado en las inscripciones sobre cerámica de Llíria (Silgo 2002, 59 y 66), y, más recientemente, Salaeco (Velaza 2015), Sertundo y Herotorag (Vidal 2016), a los que habría que añadir Belsadini según una nueva propuesta de lectura del mosaico helenístico de Elche realizada por Simón Cornago $(2019,142)$. Resulta curioso que García-Bellido aún considerara no hace demasiados años a la ibérica como una cultura sin dioses (García-Bellido 2002-2003, 228); sobre las últimas propuestas de teónimos ibéricos, véase Rodríguez Ramos, 2019; Ferrer 2019.

21 De Hoz $(2015,406)$ hablaba de "persistencia del indigenismo en época romana" para explicar esta excepcional mención; véase también Marco 2018, 309-310.

22 Rueda 2011, 132; Rueda et alii 2015, 423; Marco 2018, 306.

23 Ruiz - Molinos 2007, 31-34; Marco 2018, 307. A partir sobre todo del siglo III a.C. se documentan en los 
orientalizante en otras zonas del sur peninsular, ${ }^{24}$ con notorios ejemplos como la figura central del famoso pínax de La Serreta (Alcoi), identificada como diosa de la fecundidad al tiempo que curotrófica. ${ }^{25}$

\section{4. "Una fecundidad sincrética"26}

A propósito de lo que denominó "distinción mosaica", Assmann defendió que las culturas no solo eran capaces de generar identidades y alteridad, sino también "técnicas de traducción", técnicas que en lo referido a divinidades de panteones diferentes están atestiguadas ya en la Mesopotamia del tercer milenio a.C. Según el egiptólogo alemán, una vez que las religiones politeístas superan el etnocentrismo religioso de carácter tribal, permiten la identificación entre dioses de origen diverso a partir de su equivalencia funcional y acaban por convertirse en vehículos de traslación intercultural. ${ }^{27}$

Este proceso de traslación ideológica es especialmente evidente en las divinidades mediterráneas vinculadas a la fecundidad, para las que Olmos subrayó su carácter "receptivo y poroso" al tiempo que hablaba del "reino religioso de la polyonomasia" para describir esta capacidad de asimilación de signos y epítetos ajenos. El mismo autor remarcaba el carácter permeable del politeísmo ibérico, abierto a estímulos griegos y renovado con nombres púnicos y referentes itálicos. ${ }^{28}$ Estos estímulos, nombres y referentes tendrían una diferente acogida en las diversas áreas peninsulares: a la especial relevancia de Ártemis en el Levante y Noreste correspondería la dispensada a Astarté-Tinnit-Juno-Caelestis en las regiones del mediodía peninsular, ${ }^{29}$ con una especial incidencia del elemento púnico en el ángulo sudeste, que se convertiría allí en el principal referente del mundo indígena a la hora de adoptar elementos religiosos de raigambre mediterránea. ${ }^{30}$

Con respecto a esta especial ascendencia religiosa de lo púnico, no es ni mucho menos nuestra intención tratar en estas líneas la problemática cuestión de las relaciones entre Astarté y Tinnit, unidas, como se ha dicho, por una relación de semejanza/

santuarios ibéricos de la Alta Andalucía materiales votivos referidos a lo que podemos llamar la fecundidad humana: figuras itifálicas, úteros, senos, el propio sexo femenino y representaciones de parejas (Sánchez Moral 2016, 50), como la excepcional ofrenda metálica recuperada en Las Atalayuelas a la que hacíamos referencia anteriormente.

24 Olmos 2000-2001, 356.

25 Marín 1987, 64; Olmos 2000-2001, 367. La diosa venerada en La Serreta, llamada por algunos "la Señora" (Grau - Olmos - Perea 2008, 28), ha sido considerada como una deidad de la fecundidad cuyo culto se extendió por todo el Mediterráneo, con paralelos tan señalados como la gran diosa de Chipre (Juan 1987-1988, 326); para otros investigadores es, simplemente, "la diosa más venerada de los iberos" (Marín 2000-2001, 39-41); contra Aranegui 2011, 137. En su día se subrayó la relación de la diosa de La Serreta con Dea Caelestis Nutrix (Lucas 1981, 247 y n. 63). La presencia de la diosa se hace sentir también con fuerza en el cercano santuario de La Malladeta (Villajoyosa, Alicante), cuya principal fase de ocupación se ha determinado para los siglos II-I a.C. (Grau et alii 2017, 172), período coincidente con la primera fase de funcionamiento del santuario de Las Atalayuelas (Rueda - Molinos - Ruiz 2015, 429).

26 Olmos 2008-2009, 119.

27 Assmann 2003, 14-15.

28 Olmos 2010,61.

29 Lucas 1981, 258; Almagro 1996, 130-131. Sobre la preferencia de la forma Tinnit sobre la ya tradicional Tanit, vid. Xella 1991, 21, n. 2, con la bibliografía anterior; Lancellotti 2010, 15, n. 6.

30 Grau - Olmos - Perea 2008, 13. 
identidad difícil de descifrar. ${ }^{31}$ Tampoco es tarea fácil poder determinar con absoluta seguridad cuál de estas diosas se encuentra detrás de las menciones de divinidades greco-romanas asimilables, habiéndose constatado que el nombre de Iuno puede hacer referencia en ocasiones a Astarté y en otras a Tinnit, sin que quepa establecer un criterio unívoco de relación, circunstancia también detectada en el campo de la iconografía. ${ }^{32}$ Esta dificultad se ha hecho especialmente patente en lugares como la Península Ibérica, donde ambas diosas tuvieron una larga tradición cultual, ${ }^{33}$ lo que no hace sino remarcar lo inadecuado de una lectura de las fuentes basada en un código de traducción rígido y, sobre todo, aplicable a cualquier circunstancia. ${ }^{34}$

Pero, aun reconociendo las precauciones debidas a la hora de establecer esta especie de estratigrafía teonímica, no parece que pueda dudarse de la ascendencia que Tinnit, de la que se ha dicho que le correspondería el rol de "rappresentare il nuovo che distingue l'ecumene cartaginese", 35 ejerció sobre divinidades ibéricas locales vinculadas a la idea de fecundidad, especialmente, como se ha apuntado, en el sudeste peninsular; ${ }^{36}$ así parece corroborarlo el extenso repertorio iconográfico vinculado a esta divinidad y documentado desde hace ya varios años. ${ }^{37}$

En su relativamente reciente estudio dedicado a Dea Caelestis, Lancellotti se ha hecho eco de las dificultades a las que aludíamos anteriormente, pero defiende, como otros antes que ella misma, la continuidad de culto entre Tinnit y Caelestis, ${ }^{38}$ aunque sin

31 Lancellotti 2010, 21 y 27-28; Marín 1999, 69.

32 Bonnet 1996, 102-105; Marín 1999, 70; Lancellotti 2010, 24. Como prueba de la complejidad de estos procesos de sincretismo por lo que respecta a las diosas aquí citadas valgan expresiones como ex praecepto deae Caelestis Aug(ustae) simulacrum Iunonis Reginae, documentada en una inscripción (CIL VIII 26474) hallada cerca del santuario de la diosa en Dougga, Túnez (Golvin - Khanoussi 2005, 208); o las palabras de Agustín de Hipona: Iuno autem sine dubitatione ab illis Astarte vocatur (Aug. qu. Hept. 7.16). Se ha afirmado que "it is very difficult, if not impossible, to distinguish between Tanit and Astarte or Magna Mater, Bona Dea, others in whom the reproductive powers of the female were venerate" (Benko 2004, 25).

33 Lancellotti 2010, 29.

34 Lancellotti 2010, 22-23 y n. 12. No hace muchos años, Marín Ceballos reconocía el error de haber considerado que detrás de las referencias de Plinio a Iuno siempre se encontraba Tinnit, una vez que parece probado que también Astarté era interpretada como Hera-Iuno (Marín 2010, 502-503). En este sentido, Marco Simón expresó sus dudas sobre ciertos modelos propuestos que intentaban explicar el proceso de asimilación de los dioses romanos por parte de las culturas indígenas a partir del cumplimiento sistemático de una serie de fases que culminaban con la suplantación total de la divinidad autóctona. Estos modelos presuponían una homogeneidad difícil de probar "habida cuenta de los distintos ritmos, modalidades y soluciones que muestra el contacto cultural reflejado por nuestra documentación" (Marco 1996, 224-225).

35 Garbati 2013, 539.

36 Ramos 1989-1990, 105; Olmos 1992, 114; Poveda 1995, 359; González Alcalde 1997, 338; Moneo - Pérez - Vélez 2001, 129. Ya se habló en su día de la ascendencia de las figuras aladas de Tanit en sus homólogas de la cerámica ilicitana, consideradas como representaciones de una "deidad local, sincretizada o influida por divinidades extranjeras" (Marín 1987, 68).

37 Marín 1987; Moneo 2003, 432-433.

38 Un repaso bibliográfico sobre esta continuidad en Lancellotti 2010, 15-19; entre algunos de los partidarios de esta última, García y Bellido 1954, 9; Le Glay 1975, 130; Bloch 1975, 118-119; Marín 1999, 74; Garbati 2013, 533-534; contra Lipiński, 1995, 148 y 151, quien retomó una idea ya enunciada hace casi un siglo por Gsell (Lancellotti 2010, 16) que veía a Astarté como el antecedente directo de la Dea Caelestis romano-africana. La diosa Tinnit fue adoptada por Roma mediante el rito de la evocatio hacia el 146 a.C., en el contexto de la Tercera Guerra Púnica, asimilándose inicialmente a Juno (Macr. Sat. 3.9.7-11; vid. Lancellotti 2010, 42-43), motivo por el cual la frustrada colonia que fundó Gayo Graco en 122 a.C. sobre los restos de la capital cartaginesa (Plu. CG 9.2) fue llamada Iunonia Carthago. Casi inmediatamente se le añadiría el epíteto Caelestis (Bloch 1975, 118), que acabó por denominar en solitario a la divinidad, sobre todo a partir de los Severos (Marín 1999, 74), mostrando, además, su perfecta asimilación a otras diosas como Cibeles, Diana, Fortuna, Venus e Isis (Le 
menoscabo de reconocer que ciertos rasgos pudieron derivar de la figura de Astarté. ${ }^{39}$ La autora italiana considera la pequeña cabeza de caliza con inscripción hallada en las proximidades del santuario indígena documentado en el yacimiento de Torreparedones (Baena-Castro del Río, Córdoba) como la prueba más antigua de su culto en Hispania, ${ }^{40}$ matizando que, a pesar de la mención inequívoca a la diosa, 41 "non si debe però pensare a un santuario dedicato a questa dea, in quanto si tratta di un luogo di culto ibérico". ${ }^{42}$

La cabeza con inscripción de Torreparedones se ha interpretado como la ofrenda depositada por un fiel que pudo encontrar en el santuario un lugar sagrado o numinoso donde le resultaba más fácil la aproximación a sus propios dioses, ${ }^{43}$ si bien no se ha descartado que tuviera que ver con que allí se adorara "si no la propia Tanit, una divinidad indígena de rasgos y atribuciones parecidas que se servía de la iconografía de aquella". ${ }^{44}$ A esta última posibilidad apuntan otros indicios, como el exvoto que representa una dama entronizada, posiblemente leontocéfala, identificada con la gran diosa de Cartago, ${ }^{45}$ o la columna con capitel foliáceo documentada en la cella del santuario, considerada como una posible representación anicónica de la diosa y para la que existe algún paralelo norteafricano. ${ }^{46}$ En definitiva, en Torreparedones se ha visto "el más rico registro arqueológico relativo al culto de Tanit en el mediodía peninsular", ${ }^{47}$ por lo que, aun con todas las cautelas, se puede llegar a pensar en un complejo proceso de interpretatio, o al menos de estrecha afinidad, con la diosa local allí venerada, de la que se ha afirmado sería "una diosa madre propiciadora de la salud y la fecundidad, aspecto este último que quedaría ratificado por la presencia de figuras desnudas y, sobre todo, grávidas entre los exvotos". ${ }^{48}$ De este modo, la

Glay 1975, 139). La relación Tinnit-Juno explica que Aníbal eligiera el templo que esta última diosa tenía en Lacinium para dedicar un altar con una larga inscripción en púnico y griego en la que recordaba sus logros (Liv. 27.46.16; Plb. 3.33.18; vid. Benko 2004, 28). Sobre el culto a Dea Caelestis, al trabajo ya mencionado de Lancellotti 2010 hay que añadir el clásico de Halsberghe 1984.

39 Lancellotti 2010, 29.

40 Otros indicios, seguros o sólo probables, del culto de Caelestis en la Península en Lancellotti 2010, 68-71; entre estos no figuran algunos considerados por otros autores, como los procedentes del Tossal de Manises y La Albufereta de Alicante (Poveda 1995; Moneo 2003, 433), el templo tetrástilo erigido en Ilici, atestiguado en los sémises que acuñó la ciudad durante los años 13-12 a.C. (Beltrán 1953, 60), o la desaparecida inscripción que menciona la restauración de un temp(lum) Iunonis (CIL II 3557; sobre la errónea atribución al territorio de Ilici de esta inscripción, vid. Corell 2012, n ${ }^{\circ}$ 63), concluyéndose que la documentación sobre la diosa en la Península "appare piuttosto scarna" (Lancelloti 2010, 69). De hecho, además de la ya comentada cabeza con inscripción de Torreparedones, para el ámbito del sudeste peninsular solo se contempla una inscripción procedente de Elche que alude a un altar erigido por orden de la diosa: - - - - - / iussu / dom(inae) Caeles(tis) /aram l(ibens) p(osuit) (AE 1993, 1067; HEp 5, 1995 , 29; Lancelloti 2010, 68 y 128; vid. Corell 2012, $\mathrm{n}^{\circ}$ 1, con bibliografía anterior sobre el epígrafe).

41 Si bien se han sugerido diversas lecturas del epígrafe: en su estudio inicial, Morena proponía tres posibilidades: dea Caelius, dea Cael(estis) v(otum) s(olvit) y dea Cael(estis) ius(it) (1989, 48, de donde HEp 3, 1993,161 y AE 1994, 915; 2017, 100-101 s.). Esta última era para Marín Ceballos (1994, 221) la lectura más probable de las tres, aunque ella misma proponía Dea Caele $<_{s}>$ tis, lectura aceptada por Lancellotti $(2010,128)$. La inscripción, que apareció descontextualizada, se ha datado por criterios paleográficos entre mediados del s. I a.C. (Morena 1989, 50, siguiendo el criterio de Stylow; Díaz 2008, 225) y finales de esta misma centuria e inicios de la siguiente (Poveda 1995, 363).

42 Lancellotti 2010, 69.

43 Marín 1994, 225.

44 Marín - Belén 2002-2003, 178.

45 Marín - Belén 2002-2003, 181.

46 Cunliffe - Fernández Castro 1999, 102, figs. 3.61 y 3.62; Marín - Belén 2002-2003, 181.

47 Marín - Belén 2002-2003, 183.

48 Marín - Belén 2002-2003, 178, donde destaca que la inmensa mayoría de las estatuillas antropomorfas recuperadas debieron ser representaciones femeninas. 
divinidad habría sido asimilada inicialmente a la púnica Tinnit para acabar haciendo lo propio con la romana Caelestis. ${ }^{49}$

El santuario de Torreparedones se ha incluido en un grupo de lugares de culto, dispersos por la campiña occidental de Jaén y su continuidad por la provincia de Córdoba, que responden a un patrón similar en cuanto a la distribución, ubicación y estructura general. ${ }^{50}$ En este grupo de santuarios se inscribe también el de Las Atalayuelas, que comparte con el santuario cordobés la ubicación en una ladera sur, la orientación del edificio, su disposición y organización, así como el hecho de que tanto en uno como en otro se haga patente "un indicador propio del horizonte cronológico y espacial, restringido al sudeste y Alta Andalucía: la pequeña estatuaria votiva en piedra". ${ }^{51}$ Consideremos además la expresión sorte ius $(s) u$ aparecida en el epígrafe de Las Atalayuelas, una evidencia clara de la función oracular de la divinidad que allí moraba ${ }^{52}$ y otro de los aspectos que debió compartir con la titular del santuario de Torreparedones a tenor de una cista de piedra documentada en este lugar e interpretada como el contenedor o arca en el que se depositaban las sortes con cuya extracción se recibía la respuesta divina. ${ }^{53}$ Es momento también de recordar el carácter oracular, certificado por fuentes literarias y epigráficas, para el templo que Caelestis poseía en Cartago. ${ }^{54}$

Las similitudes que podemos establecer entre Torreparedones y Las Atalayuelas no son incompatibles con cierta asimetría en nuestro conocimiento de la realidad religiosa de ambos centros. En el primero de ellos encontramos una referencia inequívoca a Dea Caelestis que puede interpretarse como evidencia un proceso de relativa continuidad en lo que se refiere al culto arraigado en este santuario, ${ }^{55}$ pero del que desconocemos casi todo lo referido a sus fases iniciales, especialmente la identidad de la deidad ibérica originaria. ${ }^{56}$ Por el contrario, en Las Atalayuelas se documenta el nombre ibérico de una divinidad, probablemente una diosa local que compartiría muchos de los rasgos de la diosa de Torreparedones y que por razones

49 Marín 1994, 223; Seco 1999, 143; Rueda 2011, 118. El aspecto maternal de Tinnit está fuera de toda duda: “È veramente una madre ('m) misericordiosa, protettrice della sfera della fecondità, delle donne disiderose di concepire o di portare serenamente a termine la gravidanza, dell'infanzie e della famiglia" (Lancellotti 2010, 26); se hace necesario recordar también los distintos epítetos documentados en el culto a la Caelestis africana que "mettono soprattutto in rilievo la sua caratteristica di madre universale" (Lancellotti 2010, 13).

50 Rueda 2011, 116.

51 Rueda 2011, 116-117.

52 Últimamente Rueda - Ruiz 2017, 173; Morena 2017, 97; Marco Simón llamó la atención sobre tres exvotos allí documentados que representan de forma esquemática dos orejas enfrentadas (Corzo et alii 2007, 252, fig. 1), considerándolos "muy pertinentes al contexto ritual de una divinidad de carácter oracular como Betatun" en tanto que permite relacionar a esta última con divinidades "que oyen o prestan oídos" a las peticiones que les dirigen sus fieles (Marco 2018, 307).

53 Cunliffe - Fernández 1999, 337; Seco 1999, 149; Morena 2017, 317 y lám. 161. Distintas fórmulas atestiguadas en otros lugares del Imperio que aluden a mandatos de la diosa recibidos en sueños o por el lanzamiento de las sortes en Seco 1999, 149.

54 Entre las primeras, Hist. Aug. Macr. 3.1; Pert. 4.2. Véase Lancellotti 2010, 81-82; cf. García y Bellido 1954, 18. La función oracular ha sido considerada como "più che típica di Tinnit", pero también de Astarté, por lo que se puede considerar como una prueba más de esta doble influencia sobre la figura de Caelestis (Lancellotti 2010,82). Lo poco probable de la práctica de las sortes en el templo de Caelestis en Cartago, así como en el de Melqart en Gades, en Marín - Jiménez 2014, 392.

55 Rueda 2011, 123; Morena 2017,98. La última fase del santuario se ha datado entre finales de época republicana y un momento avanzado del siglo I a. C., si bien el edificio habría sustituido a otro más antiguo, en funcionamiento a mediados del s. III a.C., que, a su vez, habría reemplazado a un recinto anterior (Seco 1999, 138).

56 Rueda 2011, 132. 
desconocidas no se había asimilado a Tinnit o a Caelestis, ${ }^{57}$ pero de cuyo culto se ha dicho que estaría basado en una "autoconsciencia de fundamentar sobre la memoria del pasado" plasmada en la continuidad de pautas rituales que remontarían a época ibérica plena. ${ }^{58} \mathrm{Y}$ todo ello enmarcado en un edificio de nueva planta erigido en el siglo II a.C., profundamente reformado en la centuria siguiente, ${ }^{59}$ y concebido para albergar un culto con una fuerte impronta púnica que acabaría reconduciéndose hacia los parámetros propios de la religión romana. ${ }^{60}$

Estas matizaciones son necesarias para entender en toda su extensión otro de los paralelismos detectados entre Torreparedones y Las Atalayuelas y que hemos eludido de manera consciente hasta este momento: ambos son santuarios vinculados a una ciudad y ubicados extramuros ad portas,${ }^{61}$ un tipo de santuario para el que se ha subrayado su reiterada vinculación con el agua al actuar como marco en el que se llevaban a cabo rituales que debían celebrarse fuera de la población. ${ }^{62}$

\section{Agua y culto}

La importancia del agua para las culturas de la Antigüedad trasciende el papel meramente funcional como elemento básico para cualquier forma de vida. Su función religiosa es constatable tanto entre aquellos grupos humanos cuyos problemas de sobreexplotación de los recursos hídricos podrían explicar su carácter sacro como entre los que son ajenos por completo a los problemas que comportaría su escasez. El caos primordial acuático, común a tantos relatos cosmogónicos, y la posterior conversión del agua en elemento benéfico para el hombre en el momento en que el universo se estructura y ordena, no es sino uno de los indicios que permiten intuir su importancia en los complejos religiosos no sólo de la Antigüedad, pero especialmente de esta última. ${ }^{63}$ La sacralidad inherente al agua ${ }^{64} \mathrm{y}$, con ella, la simbología que adquiere en diversos contextos religiosos, tiene su plasmación en la gran cantidad de cultos documentados en torno a fuentes, ríos, lagos y otros acuíferos en todas las culturas mediterráneas antiguas, ${ }^{65} \mathrm{y}$ entre ellas, evidentemente, la ibérica.

No creemos necesario desarrollar la importancia del líquido elemento en la religión de los iberos, un aspecto sobre el que se lleva décadas insistiendo. ${ }^{66} \mathrm{De}$ hecho se ha llegado a defender la relación sistemática entre los santuarios ibéricos

\footnotetext{
Molinos - Rueda 2011, 233; Marco 2018, 30. De Hoz 2015, 406, hablaba de "persistencia del indigenismo en época romana" para explicar la perduración del teónimo y su reflejo epigráfico.

Rueda 2011, 128.

Rueda - Ruiz 2017, 173.

Rueda 2011, 117.

Molinos - Rueda 2011, 233; Moneo 2003, 288.

Prados 1994, 135-136; Moneo 2003, 290.

Díez de Velasco 1998, 7-8.

64 El agua, y más concretamente el agua pura o viva, se erige en la sustancia mágica por excelencia, lo que explica su carácter purificador y salutífero, así como su capacidad de conferir la vida eterna. Estos aspectos se expresan en ámbitos tan distintos como el primer ashtaka del Rig Veda y las obras de Tertuliano (Tert. Bapt. 3.4: primus liquor quod viveret edidit, ne mirum sit in baptismo si aquae animare noverunt).

65 Que explica frases como nullus enim fons non sacer (Serv. Aen. 7.84).

66 Sin pretender ser exhaustivos, véase Llobregat 1981; Olmos 1992; Prados 1994; Blázquez - García-Gelabert 1997; Blázquez 2000-2001; San Nicolás - Ruiz 2000, 102-105; Egea 2010.
} 
y el agua, especialmente en su función terapéutica ${ }^{67} \mathrm{Y}$ si bien tal relación ha sido matizada últimamente, ${ }^{68}$ no puede negarse para el caso varias veces aludido del santuario de Torreparedones, junto al que todavía hoy en día mana la conocida como Fuente de la Romana o Pilar de las Vírgenes. Su ubicación a $180 \mathrm{~m}$ al sudeste de la muralla del oppidum y a unos $325 \mathrm{~m}$ del santuario permite adjudicarle un papel en la dinámica cultual de este último. ${ }^{69}$

La importancia intuida del agua en el santuario de Torreparedones casa perfectamente con las distintas hipóstasis que adoptó la deidad allí venerada. Es conocido que los lugares dedicados a Tinnit estaban relacionados de alguna forma con el agua. Así se constata en el santuario hallado debajo del posible ninfeo de época romana en la plaza de armas de Melilla, muy cercano al único manantial natural de la ciudad, ${ }^{70}$ o en la cueva de Es Cuieram y en Illa Plana, ambas en Ibiza. ${ }^{71}$ Se ha subrayado la función de la diosa como reguladora del agua fecundante en santuarios púnicos,${ }^{72}$ pero también en territorios de comunidades ibéricas tal y como Ilici,${ }^{73}$ caso este último sobre el que volveremos más adelante.

Respecto a Dea Caelestis quizá sólo sea necesario recordar que Tertuliano la caracterizaba como la diosa que prometía las lluvias, ${ }^{74}$ erigiéndose en garante de las cosechas y en numen de la fecundidad según palabras de García y Bellido. ${ }^{75}$ Además de ejemplos tan evidentes como las fuentes ubicadas junto a la entrada del templo que la diosa tenía en la localidad tunecina de Dougga, ${ }^{76}$ su vinculación con el agua aparece con toda claridad en el reverso de las monedas del tipo Virgo Caelestis acuñadas durante el reinado de Septimio Severo, ${ }^{77}$ con la diosa portando cetro y rayo en su mano derecha y cabalgando un león debajo del cual fluye el agua surgida de un roquedo situado a la izquierda del campo monetal (Fig. 1). La explicación de este motivo la proporcionó hace ya más de un siglo Babelon, quien consideró la roca de la que mana el caudal como una representación del Mons Zeugitanus (Djebel Zaghouan), donde se captaban las aguas conducidas hasta Cartago por el

67 Blázquez 1977, 326.

68 García Cardiel 2015, 97. Los abusos cometidos en torno al culto a las aguas han provocado cierto rechazo a lo que algún investigador francés llamó "naturalisme religieux et ses avatars romantiques" (Scheid 2008, 624).

69 Seco 1999, 146. Las aguas del manantial son ricas en bicarbonatos y sulfatos, recomendables para enfermedades como la gota, el reumatismo o la artritis (Lacort et alii 1997, 141). Morena relacionó la existencia de esta Fuente de La Romana con "una inscripción hallada en el entorno de Torreparedones en la que se menciona a Isis Pelagia" (Morena 2017, 297). A pesar de que la alusión carece de la preceptiva referencia al CIL II o a cualquier otro repertorio epigráfico, creemos que se trata en realidad de la dedicatoria funeraria de Iulia Pelagia (CIL $\mathrm{II}^{2} / 5,428$ ), hallada en el cercano lugar conocido como Cerro de los Términos e interpretada como prueba de un sincretismo Isis-Caelestis en los últimos momentos de vida del santuario, circunstancia que explicaría también la presencia en este centro de exvotos con forma de pie (Seco 1999, 145).

70 Fernández Uriel 2004, 159-160.

71 Aubet 1982, 10; Olmos 1992, 106.

72 En este sentido son interesantes las observaciones de Benko sobre el carácter lunar de Tinnit y el fenómeno del rocío, una forma de precipitación importante en zonas con problemas hídricos: "No wonder then that Tanit was worshipped as a goddess of fertility, of that creative moisture in which impregnation takes place and life begins". El mismo autor se hace eco de la teoría que defiende que el nombre de la diosa "may have a connection with the watery element of the sea" (Benko 2004, 23-24); una idea muy distinta sobre el origen del teónimo en Lipiński 1995, 199-200 y 425.

73 Olmos 1992, 114.

74 Ista ipsa Virgo Caelestis Pluviarum Pollicitatrix (Tert. Apol. 22.6).

75 García y Bellido 1954, 8; Halsberghe 1984, 2207.

76 Friedheim 2006, 73.

77 RIC IV/1, $\mathrm{n}^{\circ} 193,266,267 \mathrm{~A}, 267 \mathrm{~B}$ 
impresionante acueducto de $92 \mathrm{~km}$ (17 sobre arquería) construido en época de Adriano y Antonino Pío, mientras que el rayo no sería sino un símbolo de las beneficiosas lluvias que aseguraban la pervivencia de los acuíferos de los que se abastecía la gran metrópoli norteafricana. ${ }^{78}$
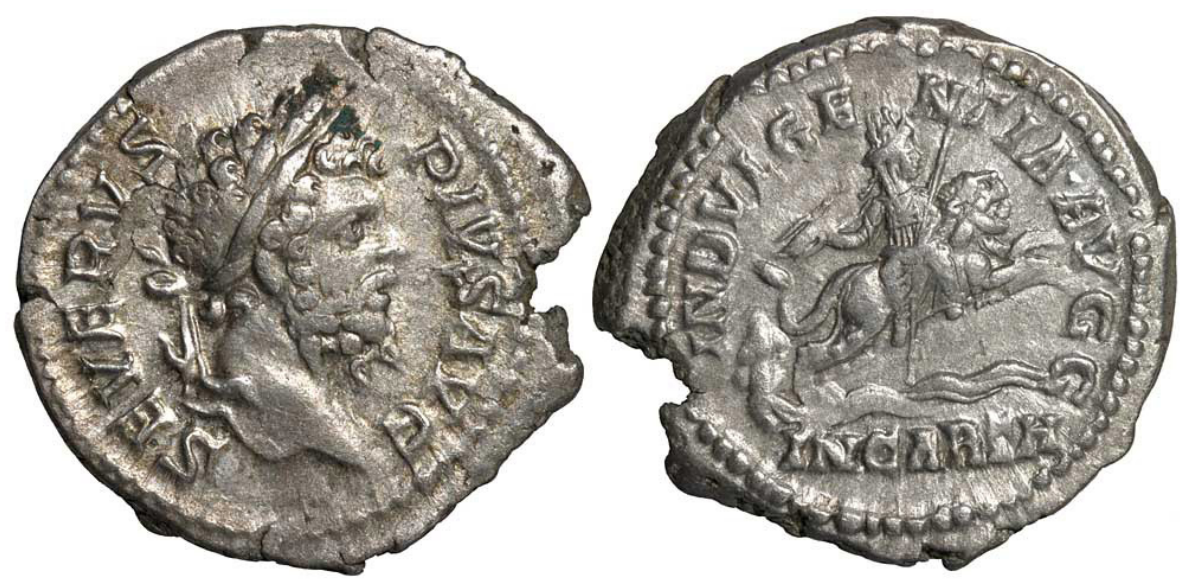

Fig. 1. Denario del tipo Virgo Caelestis acuñado en la ceca de Roma (RIC IV 266) ${ }^{79}$

Así pues, tanto por la fuente cercana como por la naturaleza de las divinidades, o distintas hipóstasis de una misma divinidad ancestral allí venerada, podemos concluir que el agua constituía un elemento importante en la dinámica cultual de Torreparedones. Y puesto que hemos recurrido en varias ocasiones al paralelismo entre este santuario y el de Las Atalayuelas, la pregunta que cabe plantearse en este momento es si también en el caso de este último se puede constatar la relación con un acuífero. Y lo cierto es que no hemos encontrado referencias a esta posibilidad en la bibliografia que hemos consultado, si bien se ha subrayado la presencia de vajilla relacionada con el rito de la libación, ${ }^{80}$ algo bastante habitual, por otro lado, en las prácticas cultuales ibéricas. ${ }^{81}$

Ante tal panorama se imponía el estudio cartográfico del territorio en el que se ubica el santuario para intentar localizar cualquier indicio que nos permitiera responder a la cuestión planteada. Recordemos que el yacimiento que aquí nos ocupa es conocido de manera genérica como (Las) Atalayuelas, nombre que toma

78 Babelon 1903, 165 y 170. A pesar de esta ya centenaria explicación, persiste hoy en día la idea que considera la corriente representada en estas monedas como alusión a un hipotético acueducto construido por Septimio Severo o, en todo caso, a la reparación del ya existente. Así, sobre el motivo comentado podemos leer que "it appears to be connected with the city's water supply (perhaps a new aqueduct), but the details are not known" (Sear 2017, 451); argumentos similares pueden encontrarse en las páginas webs http://aeternitas-numismatics. blogspot.com/2015/02/indvlgentia-avgg-in-carth-septimio.html y http:/www.romanaqueducts.info/aquamint/ romancoins.html. Además de la ausencia de pruebas arqueológicas, Babelon (1903, 168-169) ya dejó claro que la alusión a la indulgencia de los augustos que acompaña a la imagen comentada (INDVLGENTIA AvGG $\cdot$ IN CARTH $\cdot$ ) no podía referirse a la relación de trabajos públicos.

79 https://www.forumancientcoins.com/moonmoth/coins/sep_sev_039.html [consultado el 2-5-2019].

80 Rueda et alii 2015, 431.

81 Izquierdo 2003; Rueda 2011, 127. 
de la cordillera, de modesta altura (cota máxima de $601 \mathrm{~m}$ ), pero de importante relevancia topográfica, formada por varias lomas: en el centro los cerros del Portichuelo y de Las Atalayas, hacia el este el del Morrón, mientras que a occidente encontramos el ya mencionado Cerro de las Norias ${ }^{82}$ en cuya ladera sur se localiza el santuario en el que se rendía culto a nuestra Betatun, presumiblemente como divinidad patronal. ${ }^{83}$ El lugar está repartido entre los términos municipales de Torredelcampo y Fuerte del Rey, aunque se encuentra muy cerca del núcleo urbano de este último. ${ }^{84}$

$\mathrm{Y}$ es en este momento cuando cobran pleno sentido las palabras de Caro Baroja que anotábamos al inicio de nuestro trabajo, aquellas que advertían del riesgo de desenfocar la realidad si la toponimia es analizada desde la situación lingüística de un momento concreto. Porque basta con acudir al apartado dedicado a la historia del municipio en la página web del ayuntamiento de Fuerte del Rey para leer que "el núcleo que con el paso del tiempo daría lugar a la actual población de Fuerte del Rey anteriormente, ya desde tiempos del Condestable Lucas de Iranzo, era conocida (sic.) como Fuente del Rey, pequeña aldea dependiente del enorme alfoz de la ciudad de Jaén, y así se denominará durante toda la Edad Media hasta 1765, cuando pasa a denominarse como hoy en día se conoce" ${ }^{85}$ El cambio de denominación viene atestiguado en la voz doble Fuerte del Rey / Fuente del Rey del Diccionario de Madoz. Es por ello también por lo que el gentilicio de esta localidad también es doble: fuenterreño o fuerterreño. ${ }^{86}$

Con esta información no resulta arriesgado aventurar que el antiguo nombre de esta localidad jienense tiene que ver con la existencia de un acuífero cuya importancia se vería acrecentada por la escasez de agua potable de la zona y su ubicación estratégica en un punto de control de las principales vías de comunicación entre las tierras de ambas márgenes del Guadalquivir, todo lo cual explica la existencia de la fortificación medieval ya desaparecida y origen del nombre que porta la población desde $1765 .^{87}$

A día de hoy no parece que se haya determinado la ubicación exacta de la fuente en cuestión. En la citada página web del ayuntamiento no se despeja esta duda, aludiendo únicamente a la posibilidad de que se tratara de la actual fuente del Regomello, situada a poco más de medio kilómetro al WNW del actual casco urbano y a unos $2,5 \mathrm{~km}$ a vuelo de pájaro del Cerro de las Norias. No podemos descartar esta posibilidad, pero ciertos indicios toponímicos invitan a conjeturar la existencia de una surgencia mucho más cercana al lugar donde se levantó el santuario ibérico. Es el caso de la Cañada de la Fuente documentada a pocos centenares de metros al sur del Cerro de las Norias ${ }^{88}$ topónimo este último cuya segunda parte permite incluirlo

\footnotetext{
Pachón et alii 2007, 19.

83 Marco 2018, 308. La probable titularidad de Betatun sobre el santuario también es defendida por Corzo et alii 2007, 259; Rueda - Molinos - Ruiz 2015, 423; Morena 2017, 98.

84 La distancia del Cerro de las Norias al centro de la localidad es de aproximadamente 1,8 $\mathrm{km}$ en línea recta, según la medición realizada en el mapa digital disponible en http://www.geamap.com/visor-topografico-de-espana.

$85 \mathrm{http} / / / \mathrm{www}$. fuertedelrey.es/el-municipio/historia.html [consultado el 20-4-2019] (el subrayado es nuestro). La fecha del cambio de nombre es corroborada en Alcázar 2013, 201.

86 Gilabert 2015, 17.

87 Alcázar 2013, 201-202.

88 Tanto para las referencias toponímicas como para las distancias señaladas hemos utilizado las herramientas cartográficas disponibles en http://www.geamap.com/visor-topografico-de-espana y https://cartographic.info/ espana/map.php?id=487249.
} 
en lo que Villar denominó "amplia gama de apelativos para designar distintas modalidades de fenómenos acuosos" ${ }^{89}$

Por lo tanto, estamos en condiciones de plantear la posibilidad de que Betatun recibiera culto en un santuario erigido en las proximidades de lo que debió ser un acuífero de, podemos intuir, relativa importancia. Como hemos recordado en líneas anteriores, esta circunstancia no es extraña en el mundo ibérico, ${ }^{90}$ pero lo que sí es verdaderamente excepcional es conocer el nombre original de la divinidad allí adorada, nombre en el que algunos investigadores han visto, entre otros, los tractos composicionales bet ${ }^{91}$ o betun/betan, ${ }^{92}$ este último considerado también como formante de antropónimos ibéricos. ${ }^{93}$ Con todo ello, creemos que el teónimo Betatun, y es la idea central de estas páginas, comparte raíz morfológica con una serie de topónimos, antiguos y modernos, asociados a lugares en los que también se constata la presencia abundante del agua, aquellos a los que hacíamos referencia al principio de este trabajo. ${ }^{94}$

Hace ya casi treinta años, Olmos defendió la presencia de cultos o mitos relacionados con el agua en la pintura vascular ibérica, haciendo hincapié en las

\footnotetext{
Villar 2001, 271-272.
}

90 Dejando al margen la constatada importancia del agua en los santuarios rupestres ibéricos (una reciente visión de conjunto para el sudeste peninsular en Ocharán 2017) y en centros de culto extraurbanos como el Cerro de los Santos o el Santuario de la Luz, es posible que tengamos un interesante paralelo en la ciudad de Mentesa Oretana (Villanueva de la Fuente, Ciudad Real), donde la presencia de abundantes manantiales y el hallazgo de exvotos han dado a pensar en la existencia de un santuario relacionado de algún modo con las aguas (Benítez de Lugo 2004, 33). Y si bien puede parecer una obviedad el que los asentamientos humanos busquen siempre la posibilidad de aprovisionamiento fácil de agua, no es menos cierto que el concepto de naturaleza resulta inseparable de la sociedad que lo inventa y usa, por lo que estamos de acuerdo con Olmos cuando afirmaba que "no nos sirve aplicar sin más nuestra concepción al pasado para reducirlo a nuestros esquemas. Lo obvio parece trivial. No lo es." (Olmos 1998, 148).

91 Faria 2008, 67.

92 Corzo et alii 2007, 255; Rodríguez Ramos 2014, 135; reservas en Vidal 2016, 201, n. 23.

93 Como el bene-betan de Llíria, (MLH III/2, F.13.12 y 13.28), el sakar-betan de Benassal ( $M L H$ III/2, E.9.1) y el nḿlbetan de procedencia desconocida (MLH III, H.0.1Sup.); podemos añadir la variante betaŕ de Sagunt ( $M L H$ III/2, F.11.3; Corzo et alii 2007, 255), la forma tuŕgosbetan documentada en Ampuries (Rodríguez Ramos 2014, 136) y, probablemente, el betukinete de Caudete de las Fuentes (MLH III/2, F.17). La aparición hasta en tres ocasiones de beta/betan en la cuarta línea de la excepcional inscripción sobre cerámica de La Joncosa ha sido interpretada como elemento de una cadena de filiaciones con esta forma como elemento común (Panosa 2002, 340). Sobre el uso ritual de esta pieza y las de Llíria véase Silgo 2002; Rodríguez Ramos 2014, 135.

94 No creemos que la diferencia formal que supone el diptongo -ae- que aparece en Baetis, Baetulo y Baeterrae pueda ser motivo para negar en principio la relación con nuestro teónimo. Es ilustrativo en este sentido el caso de Baeterrae, transmitido por Mela con las formas Beterrae (2.75) / Beterras (2.80) y como Besara por Avieno (591). También en diversas fuentes itinerarias aparece el nombre sin el diptongo inicial, entre ellas el Itinerario de Antonino (Beterras, It. Ant. 389.5; Beterris, It. Ant. 397.1), el Anónimo de Rávena (Beterris, Rav. 341.4; Beteroris, Rav. 244.14) y la Tabula Peutingeriana (Beteris), si bien es cierto que los Vasos de Vicarello reportan la forma con diptongo en los cuatro casos (vid. Rodríguez Morales 2013, 25-26). Y si aceptamos el alto grado de fiabilidad de los topónimos transmitidos en leyendas monetales (Correa 2002,134), es obligado mencionar la forma BHTAPPATIC que aparece en las piezas acuñadas por la ceca que corresponde a la moderna ciudad de Béziers (RIG IV, $\mathrm{n}^{\circ} 69$; Rostaing 1950, 75-76); sobre el posible carácter de ultracorrección de la forma Baeterrae, véase Faria 2008, 65-66. Una diferencia similar entre la forma toponímica proporcionada por las monedas y su forma literaria la encontramos en el caso de la ciudad cuyos habitantes son mencionados por Plinio como Aesonenses (Plin. $H N 3.23$ ), identificada con la ceca ibérica que acuñó con la leyenda Eso, la actual Isona, en Lleida (Almela 2016, 14-16). Se da la circunstancia de que la ciudad responsable de estas acuñaciones ha sido considerada como "una fundación ortodoxamente romana de fines del siglo II o de inicios del I a.C. que no parece tener precedente anterior indígena de consideración" (Pérez-Almoguera 1999, 361); de hecho, la forma pliniana fue también considerada en su día como una posible ultracorrección (Mariner 1972, 295; Faria 2008, 66). 
escenas en las que en un entorno vegetal, efecto de la acción en la naturaleza del agua $\mathrm{y}$, por tanto, expresión simbólica de esta última, aparece una divinidad antropomorfa, interpretada como la plasmación de "un influjo mediterráneo que da forma humana a esta imagen originariamente numénica de la naturaleza que fecunda el agua". ${ }^{95}$ Más recientemente, el mismo autor concretaba en una serie de trabajos el estudio de esa imagen antropomorfa; hablaba así de una potnia ichthyon o "Señora de Peces", en referencia a ciertas escenas de la pintura vascular edetana, ${ }^{96} \mathrm{o}$ de la ilicitana potnia de la charca, "ninfa del agua que fluye o permanece estancada", que aparece en su epifanía rodeada de "peces y grandes aves de las charcas, animales a los que hace salir presurosos, como sus acompañantes" ${ }^{97}$ Esta última divinidad encontraría en el también ilicitano mosaico helenístico de Sailacos una de sus manifestaciones iconográficas más acabadas, ${ }^{98}$ destacando la rosa hexapétala rodeada de "una orla de ondas encrespadas, alusión inequívoca al ámbito del agua salutífera y de su diosa"; la muralla torreada que enmarca buena parte del espacio musivario es considerada como representación de la ciudad sobre la que la diosa ejerce su tutela, "cuyo centro político lo articula la vigorosa roseta y su estanque: un recinto protegido de fecundidad". 99

¿Era también nuestra Betatun una de estas divinidades vinculadas al agua y a la fecundidad a la manera de la potnia de Ilici ? $^{100}$ Como hemos indicado, estamos convencidos de que el agua tenía una presencia importante en el entorno del santuario de Las Atalayuelas, del mismo modo que creemos que la que pudo ser su diosa titular debió ejercer como numen propiciatorio de la fecundidad, en línea con las diosas a las que hacía referencia Olmos, la diosa de Torreparedones y otras documentadas en el sudeste peninsular. Por todo ello, y aun a riesgo de caer también en "una pura inspiración de advocación mariana" o en un "vascoiberismo imaginativo", ${ }^{101}$ no podemos dejar de relacionar el concepto de fecundidad y el nombre de la diosa adorada en el Cerro de las Norias con el hecho de que el verbo bete, y derivados como betete y beteta, se utilizan en el vasco actual, principalmente en los dialectos vizcaínos, con la acepción, entre otras, de "llenar, colmar, satisfacer, embarazar(se)" $\mathrm{y}$, en lenguaje familiar, "preñar". ${ }^{102}$

Olmos 1992, 112-114; véase también Lucas 1981, 249; Egea 2010, 135.

Olmos 2008-2009, 115.

Olmos 2010, 60 .

98 Las dataciones propuestas para este excepcional documento oscilan entre los siglos II y I a.C.; vid. Simón Cornago 2019, 128-129.

99 Olmos 2008-2009, 118.

100 Se ha sugerido que el culto a Betatun, como el dispensado a la divinidad de Torreparedones, también pudo tener un carácter local y directamente vinculado a la ciudad junto a la que se levantaba el santuario (Molinos - Rueda 2011, 233).

101 Rodríguez Ramos 2017, 122. En relación con esta cuestión, además de lo que en su día defendieron Tovar $(1959,36)$ y Baldinger $(1972,246)$, me gustaría traer a colación las palabras de Villar cuando mencionaba el "rechazo por hartazgo que terminaron generando los excesos vascoiberistas", al tiempo que reconocía que "el parentesco entre ibero y euskera me parece ya la única hipótesis sostenible", por lo que "todas las coincidencias entre ibero y euskera cobran una luz nueva" (Villar 2014, 259-260). Añadamos la idea expresada hace ya más de cuarenta años por un lingüista tan poco proclive a ese "vascoiberismo imaginativo" como fue Michelena, para quien era "dans ce sous-ensemble disons onomastique, que l'on trouvé la plupart des coincidences entre ibère et basque. Il y a, cela ne fait pas de doute, des acords, dont le nombre est trop élevé pour qu'on puisse les attribuer aux seuls jeux du hasard" (Michelena 1979, 37-38); en la misma línea Ballester 2001, 28-29. El propio Rodríguez Ramos (2002b, 208) afirmaba que "resulta destacable el alto porcentaje de los términos íberos de significado conocido que sí permiten un paralelo satisfactorio con el vasco".

102 Michelena 1992, s.v. Puede consultarse la versión digital del Diccionario General Vasco de la Euskaltzaindia 


\section{La cercana y acuática Deva}

En 1980 apareció en la localidad cordobesa de Cabra, distante del santuario de Las Atalayuelas unos $90 \mathrm{~km}$ por carretera, un epígrafe dedicado a la Domina Daeva, ${ }^{103}$ forma teonímica que Stylow consideró propia de "una determinada fase de la romanización del panteón indígena, a caballo entre la mención del solo nombre de la divinidad indígena sin más y la integración avanzada o completa en el panteón romano". El historiador y epigrafista alemán no dudó en considerar al numen así nombrado como una divinidad acuática vinculada a la conocida como Fuente del Río, importante surgencia kárstica que brota a kilómetro y medio al este de la población, ${ }^{104}$ especulando incluso con la idea de que el río de Cabra, originado en esta misma fuente, hubiera sido nombrado Deva en la Antigüedad. ${ }^{105}$

La idea apuntada por Stylow es coherente con la serie de hidrónimos del tipo Deba/Deva documentados en la Península Ibérica ${ }^{106}$ y por buena parte de la Europa occidental, ${ }^{107}$ nombres explicados a partir de la consideración de los cursos de agua, especialmente fuentes o manantiales, como divinidades, ${ }^{108} \mathrm{y}$ formalmente relacionados con el étimo celta $d \bar{e} v \bar{a}$, un derivado de las formas *deiva ("la divina") $\mathrm{y}$ *deivo-s ("dios"). ${ }^{109}$

Por lo tanto, de la Daeva de Cabra podemos afirmar que: 1) se trata de una divinidad indígena femenina; 2) aparece vinculada a un acuífero importante; 3) su

/ Real Academia de la Lengua Vasca en https://www.euskaltzaindia.eus/index.php?option=com oeh\&view=frontpage\&Itemid=\&lang=eu\&sarrera. Sobre estas acepciones de la voz vasca véase también Agud - Tovar 1989, s.v.; Faria 2008, 67; Trask 2008, s.v. (este último en www.sussex.ac.uk/linguistics/documents/ lxwp23-08_edb.pdf; consultado el 25-4-2019). Por su parte, Schuchardt consideró en su día la forma bethatze$r a$, documentada en la traducción al vasco del Nuevo Testamento que en 1571 realizara Joanes Leizarraga, como proveniente de bethe ("lleno"), vocablo que, en su opinión, derivó en bethatu ("llenado") "por analogía con muchos verbos románicos en $a$ " (Schuchardt 1947, 62).

103 CIL II2/5, 309: Dominae / Daevae Valeria / Com(p)se animo / lybens v(otum) s(olvit).

104 De la importancia de su caudal da fe la construcción de un acueducto, documentado epigráficamente $\left(C I L \mathrm{II}^{2} / 5\right.$, 316), que canalizaba el agua hasta el municipio de Igabrum (Goffaux 2013).

105 Stylow 1983, 300-301. Véase también Segura 1988, 171. Resulta interesante constatar que, al igual que vimos pudo ocurrir en los estadios finales del santuario de Torreparedones, también en Cabra se documenta el culto a Isis; a ello apunta tanto la inscripción en la que aparece una Flaminia Pale Isiaca Igabrens(is) (CIL II2/5, 311), como una pequeña escultura interpretada como representación del río Nilo (García y Bellido 1957, lám. XXXVI, fig. 1).

106 Ballester 2009, 313-321. Además de los potamónimos antiguos Deona (Ptol. 2.6.8) y Devales (Mela 3.1.15), los ejemplos peninsulares más conocidos de esta serie se reparten por Galicia, Cantabria, País Vasco, Teruel y Asturias. De los ejemplos asturianos destacaríamos el pequeño río que discurre junto al santuario de la Virgen de Covadonga, conocido como Deva (o Dea); así aparece ya nombrado en la relación del viaje que Ambrosio Morales llevó a cabo en 1572 por zonas del norte de la Península: "Del pie de la peña hasta una vara, o poco más del 1lano, se descuelgan dos chorros derechos de agua con gran ruido, y de otro lado sale otro gran golpe de agua, que juntándose con los chorros en una balsa, sale della el pequeño Río Deva" (Flórez 1765, 63); el hidrónimo es confirmado por Madoz (1845-1850, s.v. Covadonga). Dejaremos a un lado la posible explicación de Covadonga a partir del celta onna, "fuente, río" (Galmés 2000, 113-114), con el consiguiente paralelismo con la Dea Souconna de Châlon-sur-Sâonne a la que se asocia una fuente, documentada bajo la ciudad actual (Campbell 2012, 139) y citada entre otros por Amiano Marcelino (Amm. Marc. 15.17.11); interesa destacar ahora el carácter de la cueva asturiana como sede de un culto precristiano (Fernández Conde 2000, 499; Arias 2006, 210) dirigido a lo que se ha considerado "un numen acuático de raíz paleolítica" (Gómez 2011, 228).

107 Holder 1896, cols. 1273-1289; Delamarre 2001, s.v. deuos.

108 Ballester 2009, 314-315. En este sentido son ilustrativas las palabras de Ausonio de Burdeos: Divona Celtarum lingua, fons addite divis (Aus. Urb. 20. 33). Sobre Dīv-ona como forma latinizada de Dēvŏ-nă, derivada a su vez de *deivo-s, Holder 1896, s. vv. Dēvŏ-nă y Div-ona; Delamarre 2001, s.v. deuos.

109 Holder 1896, s.v. dēvā; Tovar 1955, 34; Delamarre 2001, s.v. deuos. 
nombre deriva del vocablo que designa, en lengua celta en este caso concreto, el concepto genérico de divinidad. Si extrapolamos estas mismas afirmaciones sobre la relativamente cercana Betatun de Las Atalayuelas, creemos que no habrá demasiado problema en aceptar las dos primeras con todo lo visto en las líneas anteriores; en cuanto a la tercera de ellas, la que implicaría asumir que en el teónimo ibérico estuviera expresada la idea de divinidad en términos absolutos, no estamos en condiciones de ofrecer una respuesta categórica, pero resulta cuando menos interesante que tal posibilidad ya la expresara hace no muchos años Rodríguez Ramos en relación con el segmento betan, presente a su juicio en el teónimo Betatun, al reconocer que le resultaba difícil sustraerse a la idea de que en aquel o en su variante bitan estuviera "la palabra íbera para "dios"". ${ }^{110}$ Lo que parece claro es que los distintos nombres que reciben las diosas en las que se concreta la sacralidad de los acuíferos no pueden ser un obstáculo para reconocer el idéntico valor funcional de estas divinidades. Así lo expresó el ya mencionado Assmann cuando defendía que "los nombres que recibe una divinidad en los diferentes países no son revelados, sino que constituyen una respuesta cultural específica a una naturaleza general". ${ }^{111}$

\section{Conclusión}

En su De natura deorum, Cicerón pone en boca del escéptico Cota el deseo de querer saber "a qué Hércules hemos de rendir culto preferentemente, porque quienes escrutan la literatura más esotérica y secreta nos transmiten más de uno". ${ }^{12} \mathrm{El}$ famoso orador romano seguía con toda una relación de divinidades para las que el nombre único no ocultaba su carácter plural: hablaba entre otros de tres dioses Júpiter, cinco Mercurios, tres Esculapios, cuatro Apolos ${ }^{113} \mathrm{y}$, por lo que afecta al tema de este trabajo, consideró que de las cuatro Venus reconocidas, la cuarta "fue concebida de Siria y de Chipre; es la llamada Astarté, que, según la descripción, se desposó con Adonis". ${ }^{14}$ Se entiende así que Bonnet afirmara que "l'Astarté de Kition n'est pas la même que celle d'Eryx, en dépit de leur nom semblable (...). Les fidèles de l'un et l'autre lieu de culte étaient-ils du reste au courant de l'existence de toutes ces Astarté? Ce n'est pas sûr". ${ }^{115}$

Por lo que atañe al ámbito religioso ibérico, Olmos hablaba en términos parecidos cuando pedía que se abandonara de una vez por todas el concepto decimonónico de

110 Rodríguez Ramos 2014, 136. Bien es cierto que el mismo autor matizó posteriormente que "es tentador entender que fuese (betan) una palabra con un significado similar a 'dios', aunque esto no es más que una idea y en algunas inscripciones formas similares, como bitan, podrían formar parte del léxico votivo, lo que, sin ser incompatible, da un margen interpretativo más amplio". Esta idea, sin embargo, no le impidió concluir que "podemos adoptar provisionalmente su interpretación como 'dios' / 'espíritu' o similar, mientras la evidencia no nos muestre una solución mejor" (Rodríguez Ramos 2017, 135; véase también 2019, 269). De todos modos, últimamente el mismo Rodríguez ha cuestionado la ibericidad de Betatun y ha propuesto interpretarlo como bitu y atun (Rodríguez Ramos 2019, 263).

111 Assmann 2008, 65. Es este buen momento para recordar las palabras que Apuleyo pone en boca de la diosa Isis: "Soy la madre de la inmensa naturaleza, la dueña de todos los elementos, el tronco que da origen a las generaciones (...). Soy la divinidad única a quien venera el mundo entero bajo múltiples formas (...). Para unos soy Juno, para otros Bellona, para los de más allá Rhamnusia" (Apul. Met. 11.5.1-3; trad. Rubio 2001).

112 Cic. ND 3.16 (trad. Escobar 2000).

113 Cic. $N D$ 3.21-23.

114 Cic. $N D$ 3.23.

115 Bonnet 1996, 143. 
la gran diosa madre mediterránea única, posible resabio del monoteísmo de nuestra cultura judeo-cristiana, y se comenzara a aceptar la diversidad de dioses y nombres divinos, atendiendo a las diferencias y cuidando los matices y las multiplicidades. Y ello sin menoscabo de reconocer la capacidad demostrada de ciertos signos (entre los que figuran la roseta, el pez, el ave y, lo que puede ser más interesante para nuestros propósitos, el agua) de mantener su vigencia a lo largo de los siglos en un contexto de "incesante intertextualidad del espacio mediterráneo". ${ }^{116}$

Por todo ello, si consideramos que "no es probable que la divinidad de San Miguel de Llíria o de la Alcudia ilicitana sea la misma diosa" ${ }^{117}$ tenemos que concluir que nuestra Betatun debió ser distinta a las titulares de muchos de los santuarios documentados en el sudeste peninsular, aunque compartiría con ellas ese horizonte en el que se manifestaba el poder fecundo de la naturaleza, según palabras ya comentadas de Marco Simón. ${ }^{118} \mathrm{La}$ aparición de su nombre en un contexto cultual centrado en un santuario que, esperamos haber demostrado, se encontraba próximo a un acuífero importante y toda la serie de argumentos que con mayor o menor acierto hemos desarrollado en las líneas precedentes, nos autorizan a plantear como hipótesis que el teónimo Betatun, si bien pudo no abarcar todos los aspectos de la naturaleza de la divinidad que lo portaba, ${ }^{119}$ expresaría al menos su carácter de lo que nos hemos atrevido a llamar Aqua Mater ${ }^{120}$ en tanto que numen vinculado a ese poder metamórfico y fecundante del agua y que, como esta, pudo ser considerada por sus cultores como "fons et origo y matriz de todas las posibilidades de existencia". ${ }^{121}$

\section{Referencias bibliográficas}

Agud, M. - Tovar, A. (1989): "Materiales para un Diccionario Etimológico de la Lengua Vasca (VI)", Anuario del Seminario de Filología Vasca Julio de Urquijo XXIII/3, 897954.

116 Olmos 2008-2009, 108.

117 Olmos 2008-2009, 119.

118 Marco 2018, 307.

119 Sobre la vertiente terapéutica de esta divinidad, Corzo et alii 2007, 259; Rueda 2011, 127; Rueda - Ruiz 2017, 173; Marco 2018, 309. Hornung 1999, 67, ya dejó bien claro en su día que los teónimos egipcios cuyo significado conocemos no explican todos los matices de las divinidades correspondientes; un ejemplo perfecto lo encontramos en el dios creador Khnum, cuyo nombre, probablemente relacionado con la palabra empleada para "pozo", no puede comprender los múltiples aspectos de su naturaleza.

120 En su conocido Onomasticon Cataloniae, Coromines se ocupaba de la serie de hidrónimos de origen indoeuropeo formados a partir de mātrēs y sus derivados, explicándolos "per una comparació de les déus amb unes mares o matrius de les aigües"; de los topónimos derivados de matrona, tal y como el valenciano Sierra de Martés o de Madrona, el lingüista catalán destacaba que solían vincularse a lugares que "són en un vessant d'on baixen aigües, o vora una font, o en terra d'aiguamolls" (Coromines 1996, s.v. Madres). En otros ámbitos hispánicos encontramos ejemplos tan ilustrativos en formas hidronímicas como Madre del Agua o Madredauga, que recuerdan al mãe-d'água portugués, u Oyu la Madre, esta última en el impresionante nacimiento del asturiano río Casaño (Sordo 2005, 291); sobre esta misma cuestión, Llamazares 2001; Ballester 2009, 315-317. Para otros ámbitos europeos, además del clásico Matrona (actual Marne), nombrado entre otros autores antiguos por César en los primeros compases de su de bello Gallico (Caes. Gal. 1.1.2), véase entre otros Holder 1896-1919, s.v. Mátr-ŏna; Delamarre 2001, s.v. matir.

121 Eliade 1954, 185. 
Alcázar Hernández, E. M. (2013): “Las fortificaciones del concejo fronterizo de Jaén”, [en] I. C. F. Fernandes (coord.), Fortificações e Território na Península Ibérica e no Magreb (séculos VI a VI), Lisboa, 199-208.

Almagro Gorbea, M. (2002): "Una probable divinidad tartésica identificada: Niethos/Netos", Palaeohispanica 2, 37-70 (https://doi.org/10.36707/palaeohispanica.v0i2.347).

Almagro, M. - Moneo, T. (2000): Santuarios urbanos en el mundo ibérico (=Publicaciones del Gabinete de Antigüedades de la Real Academia de la Historia. Bibliotheca Archaeologica Hispana 4), Madrid.

Alonso, Á. - Garabito, T. - Crespo, S. (coords.), (1999): Homenaje al profesor Montenegro: estudios de historia Antigua, Valladolid.

Álvarez, J. (1951): "Les noms hispaniques des fleuves avec racines de valeur eau", IIIe Congrès International de Toponymie et d'Antroponymie, Louvain, 201-203.

Amela Valverde, L. (2016): "Localización de las cecas ibéricas del sistema del denario del noreste de la Península Ibérica", Gaceta Numismática 191, 3-57.

Aranegui, C. (2011): "Lo divino en femenino”, [en] Blánquez Pérez (ed.), 2011, 133-158.

Arias Páramo, L. (2006): “Aproximación a la realidad material del monacato asturiano en la Alta Edad Media”, [en] J. A. García de Cortázar - R. Teja (coords.), Monjes y monasterios hispanos en la Alta Edad Media, Salamanca, 205-228.

Assmann, J. (2003): Moisés el egipcio, Madrid.

Aubet Semmler, Ma E. (1982): El Santuario de Es Cuieram (=Trabajos del Museo Arqueológico de Ibiza 8), Ibiza.

Babelon, E. (1903): "Les monnaies de Septime Sévère, de Caracalla et de Géta relatives à l'Afrique", Rivista di Numismatica XVI/2, 157-174.

Baldinger, K. (1972): La formación de los dominios lingüísticos en la Península Ibérica (=Gredos. BRH, Tratados y monografías 10), Madrid.

Ballester, X.

(2001): "La adfinitas de las lenguas aquitana e ibérica", Palaeohispanica 1, 21-33.

(2009): "Deva y otros devaneos arqueoibéricos", ELEA 9, 313-346.

(2013): "Hidronimia con los cinco sentidos", Agua y vida 3, 187-226.

Beltrán, A. (1953): "Los monumentos en las monedas hispanorromanas", AEspA 26, 39-66.

Benítez de Lugo Enrich, L. (2004): “Arqueología del culto ibérica en la Oretania septentrional”, Arse 38, 29-61.

Benko, S. (2004): The Virgin Goddess: Studies in the Pagan and Christian Roots of Mariology (=Studies in the Pagan and Christian Roots of Mariology 59), Leiden (http:// dx.doi.org/10.1163/9789047412588).

Blánquez Pérez, J. (ed.), (2011): ¿Hombres o dioses?: Una nueva mirada a la escultura del mundo ibérico, Madrid.

Blázquez, J. M ${ }^{\mathrm{a}}$

(1977): Imagen y Mito. Estudios sobre religiones mediterráneas e iberas, Madrid.

(2000-2001): "Nuevas aportaciones a la religiosidad ibérica", Lucentum XIX-XX, 149182 (https://doi.org/10.14198/LVCENTVM2000-2001.19-20.10).

Blázquez, J. M M $^{\mathrm{a}}$ García-Gelabert, Mª P. (1997): "El culto a las aguas en la Hispania prerromana", [en] Peréx Agorreta (ed.), 1997, 105-115.

Bloch, R. (1975): "Processus d'assimilations divines dans l'Italie des premiers siècles",[en] Dunand - Lévêque (eds.), 1975, 112-122 (https://doi.org/10.1163/9789004295131_007).

Bonnet, C. (1996): Astarté. Dossier documentaire et perspectives historiques (=Studi Fenici

37. Contributi alla Storia della Religione Fenicio-Punica 2), Roma.

Campbell, B. (2012): Rivers and the Power of Ancient Rome, Chapel Hill. 
Caro Baroja, J. (1986): El laberinto vasco, Madrid.

Castro López, M. - López Rozas, J. - Zafra de la Torre, N. - Crespo García, J. M ${ }^{\mathrm{a}}-$ Choclán Sabina, C. (1990): "Prospección con sondeo estratigráfico en el yacimiento de Atalayuelas, Fuerte del Rey (Jaén)", Anuario Arqueológico de Andalucía de 1987. II. Actuaciones sistemáticas, 207-215.

Cazabán Laguna, A. (1920): "En Fuerte del Rey. Buscando curiosidades arqueológicas”, Don Lope de Sosa 95, 342-348.

Cebrián Abellán, A. - Cano Valero, J. (eds.), (1992): Relaciones topográficas de los pueblos del reino de Murcia (1575-1579), Murcia, 1992.

Clavel, M. (1970): Béziers et son territoire dans l'Antiquité (=Annales littéraires de l’Université de Besançon 112), Paris (https://doi.org/10.3406/ista.1970.1013)

Colbert de Beaulieu, J.-B. - Fischer, B. (1998): Recueil des Inscriptions Gauloises (R.I.G.). Vol. IV: les légendes monétaires, Paris (=RIG IV).

Corell, J. (2012): Inscripcions romanes del País Valencià, 6: Ilici, Lucentum, Allon, Dianium $i$ els seus territoris, Valencia.

Coromines, J. (1996): Onomasticon Cataloniae, V, Barcelona.

Correa, J. A. (2002): "La distribución de las oclusivas orales en la toponimia prerromana de la Bética”, Palaeohispanica 2, 133-139.

Corzo, S. - Pastor, M. - Stylow, A. - Untermann, J. (2007): “Betatun, la primera divinidad ibérica identificada", Palaeohispanica 7, 251-262.

Cunliffe, B. - Fernández Castro, Ma C. (1999): The Guadajoz Project. Andalucia in the First Millenium B. C., Volume I: Torreparedones and its Hinterland (=Oxford University Committee for Archaeology. Monograph 47), Oxford.

Delamarre, X. (2001): Dictionnaire de la langue gauloise. Une approche linguistique du vieux-celtique continental, Paris.

Díaz Ariño, B. (2008), Epigrafía latina republicana de Hispania (=Universitat de Barcelona. Col·lecció Instrumenta 26), Barcelona.

Díez de Velasco, F. (1998): Introducción a la historia de las religiones. Hombres, ritos, dioses, Madrid.

Dunand, Fr. - Lévêque, P. (eds.), (1975): Les syncrétismes dans les religions de l'Antiquité (=Études préliminaires aux religions orientales dans l'Empire romain 46), Leiden (https:// doi.org/10.1163/9789004295131).

Egea, A. (2010): "La cultura del agua en época ibérica: una visión de conjunto", Lucentum XXIX, 119-138 (https://doi.org/10.14198/LVCENTVM2010.29.07).

Eliade, M. (1954): Tratado de Historia de las Religiones, Madrid.

Faria, A. Marques de (2008): “Crónica de onomástica paleohispânica (14)”, Revista Portuguesa de Arqueologia 11, 57-102 (https://doi.org/10.1016/S0873-2159(15)30298-1).

Fernández Conde, F. J. (2000): La religiosidad medieval en España I. Alta Edad Media (s. VII-X), Oviedo.

Fernández Uriel, P. (2004): “La moneda de Rusaddir. Una hipótesis de trabajo”, Gerión 22/1, 147-167.

Ferrer i Jané, J. (2019): “Construint el panteó ibèric amb l'ajut de les inscripcions ibèriques rupestres", Ker. Revista del club de Recerca de Cerdanya 13, 42-57.

Flórez, E. (ed.), (1765): Viage de Ambrosio de Morales por orden del rey D. Phelipe II. A los reynos de León, y Galicia, y Principado de Asturias, Madrid.

Friedheim, E. (2006): Rabbinisme et Paganisme en Palestine romaine (=Religions in the Graeco-Roman World 157), Leiden-Boston (http://dx.doi.org/10.1163/978904740 8277). 
Galmés de Fuentes, A. (2000): Los topónimos: sus blasones y trofeos (la toponimia mítica), Madrid.

Garbati, G. (2013): “Tradizione, memoria e rinnovamento. Tinnit nel tofet di Cartagine”, [en] O. Loretz - S. Ribichini - W. G. E. Watson - J. A. Zamora (eds.), Ritual Religion and Reason. Studies in the Ancient World in Honour of Paolo Xella (=Alter Orient und Altes Testament 404), Münster, 529-542.

García y Bellido, A.

(1954): El culto a Dea Caelestis en la Península Ibérica, Madrid.

(1957): "Isis y el collegium Illychiniariorum del Pratum novum (Conventus Cordubensis)", [en] Hommages à Waldemar Deonna (=Coll. Latomus 28), Bruxelles, 238-244.

García-Bellido, M ${ }^{a}$ P. (2002-2003), "Gestos de poder divino en la imaginería ibérica", CuPAUAM 28-29, 227-240 (https://doi.org/10.15366/cupauam2003.29.011).

García Cardiel, J. (2015): "El Cerro de los Santos: paisaje, negociación social y ritualidad entre el mundo ibérico y el hispano", AEspA 88, 85-104 (https://doi.org/10.3989/ aespa.088.015.005).

Gilabert Carrillo, J. (2015): “Topónimos mayores de la provincia de Jaén y sus gentilicios", Argentaria 10, 3-43.

Goffaux, B. (2013): “CIL, II $2 / 5,316$ (Igabrum) y la cronología de los primeros flamines provinciales de la Bética”, AEspA 86, 261-278 (https://doi.org/10.3989/ aespa.086.013.015).

Golvin, J.-C. - Khanoussi, M. (dirs.), (2005): Dougga, études d'architecture religieuse: les sanctuaires des Victoires de Caracalla, de "Pluton" et de Caelestis (=Ausonius Éditions. Collection Mémoires 12), Bordeaux.

Gómez Tabanera, J. M. (2011): "La hermenéutica de Covadonga”, [en] L. Garagalza (coord.), Filosofia, Hermenéutica y Cultura. Homenaje a Andrés Ortiz-Osés, Bilbao, 227-235.

González Alcalde, J. (1997): "Simbología de la diosa Tanit en representaciones cerámicas ibéricas”, Quaderns de Prehistòria i Arqueologia de Castelló 18, 329-344.

Grau Mira, I. - Amorós López, I. - Segura Martí, J. M. (2017): El santuario ibérico y romano de La Serreta (Alcoi, Cocentaina, Penàguila), Alcoi.

Grau Mira, I. - Olmos, R. - Perea, A. (2008): "La habitación sagrada de la ciudad ibérica de La Serreta", AEspA 81, 5-29 (https://doi.org/10.3989/aespa.2008.v81.38).

Grau Mira, I. - Rueda Galán, C. (2014): "Memoria y tradición en la (re)creación de la identidad ibérica: reviviscencia de mitos y ritos en época tardía (ss. II-I a.C.)", [en] T. Tortosa (ed.), Diálogo de identidades. Bajo el prisma de las manifestaciones religiosas en el ámbito mediterráneo (s. III a.C.-S. I d.C.), (=Anejos de AEspA LXXII), Mérida, 101-121.

Guillén Riquelme, M. C. (2014): Industrialización y cambio social en Mazarrón (Murcia). Estudio antropológico de una comunidad minera del siglo XIX (1840-1890), Tesis doctoral, Universidad de Murcia.

Halsberghe, G. H. (1984): "Le culte de Dea Caelestis", ANRW II, 17/4, 2203-2223 (https:// doi.org/10.1515/9783110864397-007).

Holder, A. (1896): Alt-Celtischer Sprachschatz, vol. I, Leipzig.

Hornung, E. (1999): El Uno y los Múltiples. Concepciones egipcias de la divinidad, Valladolid.

Hoz Bravo, J. J. de (2015): "La lengua ibérica en Jaén, desde el s. IV hasta las inscripciones de Piquía y las Atalayuelas", [en] Ruiz - Molinos (eds.), 2015, 393-406.

Hübner, E. (ed.), (1869): Corpus Inscriptionum Latinarum II. Inscriptiones Hispaniae Latinae, Berolini (=CIL II). 
Izquierdo Peraile, I. (2003): "La ofrenda sagrada del vaso en la cultura ibérica", Zephyrus $56,117-135$.

Juan i Moltó, J. (1987-1988): "El conjunt de terracotes votives del santuari ibèric de la Serreta (Alcoi, Cocentaina, Penàguila)", Saguntum 21, 295-330.

Lacort, P. J. - Galeano, G. - Cano, J. I. (1997): “Documentos arqueológicos y epigráficos relativos a cultos de agua en época romana en la provincia de Córdoba", [en] Peréx Agorreta (ed.), 1997, 141-147.

Lancellotti, M. G. (2010): Dea Caelestis. Studi e materiali per la storia di una divinità dell'Africa romana (=Studi Fenici 44), Pisa-Roma.

Le Glay, M. (1975): “Les syncrétismes dans l'Afrique Ancienne”, [en] Dunand - Lévêque (eds.), 1975, 123-151 (https://doi.org/10.1163/9789004295131_008).

Ledo Caballero, A. C. (1999): "El topónimo ibérico Bétera y su valor hidrográfico", [en] Alonso et alii (coords.), 1999, 335-344.

Lipiński, E. (1995): Dieux et déesses de l'univers phénicien et punique (=Orientalia Lovaniensia Analecta 64), Leuven.

Llamazares Sanjuán, A. (2001): “"Madre’ y topónimos afines en la mitad norte Peninsular”, Lletres asturianes: Boletín Oficial de l'Academia de la Llingua Asturiana 79, 85-93.

Llobregat, E. (1981): "Toros y agua en los cultos funerarios ibéricos", Saguntum 16, 149-161.

Lucas, Ma R. (1981): "Santuarios y dioses en la baja época ibérica", [en] La Baja Época de la Cultura Ibérica. Actas de la mesa redonda celebrada en conmemoración del X aniversario de la Asociación Española de Amigos de la Arqueología, Madrid, 233-293.

Madoz, P. (1845-1850): Diccionario Geográfico-Estadístico-Histórico de España y sus posesiones de Ultramar, Madrid (Badajoz, 1990).

Marco Simón, F.

(1996): "Integración, interpretatio y resistencia religiosa en el occidente del Imperio", [en] J. Ma Blázquez - J. Alvar (eds.), La Romanización en Occidente, Madrid, 217-238. (2018): "La novedad en la memoria: el dios Betatun y un ritual de plegaria familiar en el santuario ibérico de Las Atalayuelas (Fuerte del Rey, Jaén)", [en] J. M ${ }^{\mathrm{a}}$ Vallejo - I. Igartua - C. García Castillero (eds.), Studia philologica et diachronica in honorem Joaquín Gorrochategui: Indoeuropaea et palaeohispanica (=Anejos de Veleia. Series Minor 35), Vitoria-Gasteiz, 301-312.

Marín Ceballos, $\mathrm{M}^{\mathrm{a}} \mathrm{C}$.

(1987): “¿Tanit en España?”, Lucentum 6, 43-79 (https://doi.org/10.14198/ LVCENTVM1987.6.04).

(1994): "Dea Caelestis en un Santuario Ibérico", [en] A. González Blanco - J. L. Cunchillos - M. Molina (coords.), El mundo púnico. Historia, sociedad y cultura. Coloquios de Cartagena, I (=Biblioteca Básica Murciana. Extra 4), Murcia, 217-225.

(1999): "Los dioses de la Cartago púnica", [en] B. Costa - J. H. Fernández (eds.), De Oriente a Occidente: los dioses fenicios en las colonias occidentales. XII Jornadas de Arqueología Fenicio-Púnica (Eivissa, 1997), (=Treballs del Museu Arqueològic d'Eivissa e Formentera 43), Eivissa, 63-90.

(2000-2001): "La representación de los dioses en el mundo ibérico", Lucentum XIX-XX, 5-63 (https://doi.org/10.14198/LVCENTVM2000-2001.19-20.11).

(2010): "Imagen y culto de Astarté en la Península Ibérica I. Las fuentes griegas y latinas", [en] $\mathrm{M}^{\mathrm{a}}$ L. de la Bandera Romero - E. Ferrer Albelda (coords.), El Carambolo. 50 Años de un tesoro (=Editorial Universidad de Sevilla. Historia 165), Sevilla, $491-512$ (http:// dx.doi.org/10.12795/9788447221707).

Marín Ceballos, Ma C. - Belén, $M^{a}$ (2002-2003): “En torno a una dama entronizada de 
Torreparedones", Boletín de la Asociación Española de Amigos de la Arqueología 42, 177-194.

Marín Ceballos, Ma C. - Jiménez Flores, A. M. (2014): “La adivinación en el santuario de Melqart en Gadir", [en] C. Fernández - C. Ferrando - B. Costa (eds.), In Amicitia. Miscellania d'estudis en Homenatge a Jordi H. Fernández (=Treballs del Museu Arqueològic d'Eivissa e Formentera 72), Eivissa, 383-395.

Mariner Bigorra, S. (1972): “Adaptaciones latinas de términos hispánicos”, [en] Homenaje a Antonio Tovar ofrecido por sus discípulos, colegas y amigos, Madrid, 283-299.

Mattingly, H. - Sydenham, E. A. (1986): The Roman Imperial Coinage IV/1, London (=RIC IV/1).

Michelena, L.

(1979): "La Langue Ibère", [en] A. Tovar et alii (eds.), Actas del II Coloquio sobre Lenguas y Culturas Prerromanas de la Península Ibérica (=Universidad de Salamanca. Acta Salmanticensia 113), Salamanca, 23-39.

(1992): Diccionario General Vasco, vol. V, Bilbao.

Molinos Molinos, M. - Ruiz Rodríguez, A. - Rueda Galán, C. - Lozano Ocaña, G. - Wiña Garcerán, L. (2005): "Intervención arqueológica en el santuario de Las Atalayuelas. Primeras aportaciones", Anuario arqueológico de Andalucía 2002 3/1, 628-633.

Molinos, M. - Rueda, C. (2011): "Entre tradición e innovación: el imaginario religioso de los nuevos espacios de representación pública”, [en] Blánquez Pérez (ed.), 2011, 213-236.

Moneo, T. (2003): Religio iberica. Santuarios, ritos y divinidades (siglos VII-I A.C.), Publicaciones del Gabinete de Antigüedades de la Real Academia de la Historia. Bibliotheca Archaeologica Hispana 20), Madrid.

Moneo, T. - Pérez, J. - Vélez, J. (2001): "Un santuario de entrada ibérico en "El Cerro de las Cabezas" (Valdepeñas, Ciudad Real)", Complutum 12, 123-136.

Morena López, J. A.

(1989): El santuario ibérico de Torreparedones (Castro del Rí-Baena, Córdoba), (=Estudios Cordobeses 46), Córdoba.

(2017): Arquitectura, iconografía y culto en el santuario iberorromano de Torreparedones (Baena, Córdoba), T. I. Tesis doctoral, Universidad de Córdoba.

Nieto Ballester, E. (2000): "La toponimia de las fuentes en España: una nota sobre algunos resultados del lat. fonte*", Revista de Filología Española 80, 3-4, 395-406 (https://doi. org/10.3989/rfe.2000.v80.i3/4.267).

Ocharán Ibarra, J. A. (2017): Santuarios rupestres ibéricos del sureste peninsular, Tesis doctoral, Universidad de Alicante.

Olmos, R.

(1988): "Aportaciones iconográficas a las copas del siglo IV a. de C. de Cástulo: conjeturas púnicas", [en] M $\mathrm{a}$. García-Gelabert - J. M Ba Blázquez, Castulo, Jaén, España. I. Excavaciones en la necrópolis ibérica del Estacar de Robarinas (s. IV a. C.), (=BAR International Series 425), Oxford, 315-324.

(1992): "Iconografía y culto a las aguas de época prerromana en los mundos colonial e ibérico", ETF. Serie II, Ha Antigua 5, 103-120 (https://doi.org/10.5944/etfii.5.1992.4187). (2000-2001): "Diosas y animales que amamantan: la transmisión de la vida en la iconografía ibérica”, Zephyrus 53-54, 353-378.

(2008-2009): "El estanque de la diosa: representaciones de raigambre oriental y mediterránea en la iconografía ibérica", Boletín de la Asociación Española de Amigos de la Arqueología 45, 111-127.

(2010): "La ninfa Ilike", [en] T. Tortosa Rocamora - S. Celestino Pérez - R. Cazorla 
Martín (coords.), Debate en torno a la religiosidad protohistórica (=Anejos de AEspA LV), Madrid, 49-64.

Orduña Aznar, E. (2009): "Nueva interpretación de la inscripción de Betatun", Veleia 26, 359-362.

Pachón Romero, J. A. - Carrasco Rus, J. L. - Aníbal González, C. (2007): "Realidad imitada, modelo imaginado, o revisión de las tradiciones orientalizantes en tiempos ibéricos, a través de la crátera de columnas de Atalayuelas (Fuerte del Rey / Torredelcampo, Jaén)", Antiquitas 18-19, 17-42.

Panosa, M. I. (2002): "Inscripción ibérica procedente de La Joncosa (Jorba, Barcelona)", Palaeohispanica 2, 333-353 (https://doi.org/10.36707/palaeohispanica.v0i2.362).

Peréx Agorreta, Mª J. (ed.), (1997): Termalismo Antiguo, Madrid.

Pérez-Almoguera, A. (1999): "El elemento forastero en el municipio de Aeso (Isona, Lleida)", [en] Alonso et alii (coords.), 1999, 361-374.

Poveda Navarro, A. M. (1995): "IVNO CAELESTIS en la colonia hispanorromana de ILICI", ETF. Serie II, $H^{a}$ Antigua 8, 357-369 (https://doi.org/10.5944/ etfii.8.1995.4270).

Prados Torreira, L. (1994): "Los santuarios ibéricos. Apuntes para el desarrollo de una arqueología del culto", Trabajos de Prehistoria 51/1, 127-140 (https://doi.org/10.3989/ tp.1994.v51.i1.470).

Pritchard, J. B. (1978): Recovering Sarepta. A Phoenician City, Princeton, New Jersey.

Quesada Sanz, F. - Rueda Galán, C. (2017): "Las armas y el contexto del guerrero de Las Atalayuelas (Jaén): una escultura de época ibérica tardía/romano republicana”, Gladius XXXVII, 7-51 (http://dx.doi.org/10.3989/gladius.2017.01).

Ramos Fernández, R. (1989-1990): “Ritos de tránsito: sus representaciones en la cerámica ibérica", Anales de Prehistoria y Arqueología 5-6, 101-109.

Rodríguez Morales, J. (2013): "Los casos gramaticales en los Vasos de Vicarello y otras fuentes itinerarias", El Nuevo Miliario 15, 22-39.

Rodríguez Ramos, J.

(2002a): “Acerca de los afijos adnominales de la lengua íbera", Faventia 24/1, 115-134.

(2002b): "La hipótesis del vascoiberismo desde el punto de vista de la epigrafía íbera",

Fontes Linguae Vasconum 90, 197-217.

(2014): "Nuevo Índice Crítico de formantes de compuestos de tipo onomástico íberos", Arqueoweb 15/1, 81-238.

(2017): "La cuestión del dativo en la lengua íbera", Philologia Hispalensis 31/1, 119-150 (https://doi.org/10.12795/PH.2017.i31.06).

(2019): "Sobre la identificación de dioses íberos en las inscripciones", Gerión 38/1, 259284 (http://dx.doi.org/10.5209/geri.68593).

Rostaing, Ch. (1950): Essai sur la toponymie de la Provence, depuis les origines jusqu'aux invasions barbares, Paris.

Rueda Galán, C. (2011): "Modelos de interacción: la divinidad como instrumento de análisis en los procesos de la sociedad ibera (siglos III a.C.-I d.C.)", [en] A. Sartori - A. Valvo (eds.): Identità e autonomie nel mondo romano occidentale. Iberia-Italia, Italia-Iberia, III Convegno Internazionale di Epigrafia e Storia Antica (=Epigrafia e Antichitá 29), Milano, 107-140.

Rueda Galán, C. - Molinos Molinos, M. - Ruiz Rodríguez, A. (2015): "Culto, rito y ofrenda en el santuario periurbano de Las Atalayuelas (Fuerte del Rey)", [en] Ruiz - Molinos (eds.), 2015, 423-436.

Rueda Galán, C. - Ruiz Rodríguez, A. (2017): “Modelos cultuales a contraste: estrategias 
de «continuidad» en los santuarios territoriales del alto Guadalquivir (finales del siglo III a.n.e.-finales del I a.n.e.”, [en] T. Tortosa - S. F. Ramallo Asensio (eds.), El tiempo final de los santuarios ibéricos en los procesos de impacto y consolidación del mundo romano (=Anejos de AEspA LXXIX), Madrid, 161-180.

Ruiz, A. - Molinos, M. (eds.), (2015): Jaén, tierra ibera. 40 años de investigación y transferencia, Jaén.

Ruiz Rodríguez, A. - Molinos Molinos, M. (2007): Iberos en Jaén (=Centro Andaluz de Arqueología Ibérica. Textos 2), Jaén.

Ruiz Rodríguez, A. - Rueda Galán, C. - Wiña Garcerán, L. - Molinos Molinos, M. (2005): "Romanización y sincretismo religioso en el santuario de Las Atalayuelas (Fuerte del Rey - Torredelcampo, Jaén)", AEspA 78/191-192, $79-96$ (https://doi.org/10.3989/aespa.2005. v78.74).

San Nicolás, P. - Ruiz, M. (2000): Arqueología y antropología ibéricas, Madrid.

Sánchez Moral, Ma E. (2016): “¿El nacimiento mítico de un linaje? Una nueva propuesta interpretativa de la "diosa de los lobos" (Umbría de Salchite, Moratalla, Murcia)", ETF. Serie II. Ha Antigua 29, 27-56 (https://doi.org/10.5944/etfii.29.2016.16447).

Scheid, J. (2008): "Le culte des eaux et des sources dans le monde romain. Un sujet problématique, déterminé par la mythologie moderne", Annuaire du Collège de France 2007-2008. Résumé des cours et travaux 108e année, Paris, 622-637 [Recuperado el 253-2019 de https://journals.openedition.org/annuaire-cdf/122\#entries].

Schmidt, J. - Cagnat, R. (eds.), (1891): Corpus Inscriptionum Latinarum, vol. VIII: Inscriptiones Africae Latinae, Berlin (=CIL VIII).

Schuchardt, H.

(1909): “Span. Vega; nava”, Zeitschrift für Romanische Philologie 33, 462-468.

(1947): Primitiae Linguae Vasconum (=Ediciones Universidad de Salamanca. Tesis y estudios salmantinos 3), Salamanca.

Sear, D. R. (2017): Roman Coins and Their Values, vol. 2, London (1 ${ }^{\mathrm{a}}$ ed. 2002), (https://doi. org/10.2307/j.ctvk8w0s0).

Seco Serra, I. (1999): “El betilo estiliforme de Torreparedones”, SPAL 8, 135-158 (https:// doi.org/10.12795/spal.1999.i8.08).

Segura Arista, M ${ }^{\mathrm{a}}$ L. (1988): La ciudad ibero-romana de Igabrum (Cabra, Córdoba), (=Estudios Cordobeses 43), Córdoba.

Silgo Gauche, L.

(1988): "La antroponimia ibérica de Sagunto (1)", Arse 23, 67-77.

(1994): Léxico ibérico (=Sección de Estudios Ibéricos. Academia de Cultura Valenciana. ELEA 1), Valencia.

(2002): "Las inscripciones ibéricas de Liria", Arse 36, 51-79.

(2013): Estudio de toponimia ibérica. La toponimia de las fuentes clásicas, monedas e inscripciones, Madrid.

Simón Cornago, I. (2019): "Sobre la inscripción del mosaico helenístico de Ilici (La Alcudia, Elche)", Palaeohispanica 19, 123-144 (https://doi.org/10.36707/palaeohispanica. v0i19.205).

Sordo Sotres, R. (2005): Contribución al conocimiento de la toponimia y la gramática autóctonas de Asturias, Cantabria y el noreste de León (=Colección El Jogueru 9), Gijón.

Stylow, A. U. (1983): "Inscripciones latinas del sur de la provincia de Córdoba”, Gerión 1, 267-303.

Stylow, A. U. - Atencia Páez, R. - González Fernández, J. - González Román, C. - Pastor Muñoz, M. - Rodríguez Oliva, P. (eds.), (1998): Corpus Inscriptionum Latinarum II: 
Inscriptiones Hispaniae Latinae, editio altera, pars V. Conventus Astigitanus, BerlinNew York $\left(=C I L \mathrm{II}^{2} / 5\right)$.

Tovar, A.

(1955): Cantabria Prerromana o lo que la lingüistica nos enseña sobre los antiguos cántabros (=Publicaciones de la Universidad Internacional Menéndez Pelayo 2), Madrid. (1959): El euskera y sus parientes (=Biblioteca vasca 2), Madrid.

Trask, R. L. (2008): Etymological Dictionary of Basque, University of Sussex.

Untermann, J.

(1990): Monumenta Linguarum Hispanicarum III/2: Die iberischen Inschriften aus Spanien, Wiesbaden (=MLH III/2).

(2018): Monumenta Linguarum Hispanicarum VI: Die vorrömische einheimische Toponymie des antiken Hispanien, Wiesbaden (=MLH VI).

Velaza, J. (2015): "Salaeco: un teónimo ibérico", ZPE 194, 290-291

Vidal, J. C. (2016): "Interpretació ibèrica de dos teònims preromans del nord-est peninsular", Revista d'Arqueologia de Ponent 26, 195-204 (https://doi.org/10.21001/rap.2016.26.10).

Villar, F.

(2001): "Indoeuropeos y no indoeuropeos en la Península Ibérica", [en] F. Villar - M.

P. Fernández (eds.), Religión, Lengua y Cultura prerromanas de Hispania (=Ediciones Universidad de Salamanca. Acta Salmanticensia, Estudios Filológicos 283), Salamanca, 262-286.

(2014): Indoeuropeos, iberos, vascos y sus parientes (=Ediciones Universidad de Salamanca. Estudios Filológicos 340), Salamanca.

Xella, P. (1991): Baal Hammon. Recherches sur l'identité et l'histoire d'un dieu phénicopunique (=Studi Fenici 32), Roma. 